\title{
- PROCEEDINGS OF THE THIRTY-SIXTH ANNUAL MEETING OF THE AMERICAN SOCIETY FOR CLINICAL INVESTIGATION HELD IN ATLANTIC CITY, N. J., MAY 8, 1944
}

READ BEFORE THE SCIENTIFIC SESSION

Presidential Address

\author{
SOME OF THE "DO'S" AǸ "DO-NOT'S" IN CLINICAL INVESTIGATION \\ By FULLER ALBRIGHT
}

When your President and Council decided to hold this meeting, they had to ask themselves the following question put to them by the Office of Defense Transportation in Washington: Is this meeting likely to contribute to the over-all war effort? I, for one, and I think I speak for the majority of the Councillors, had no hesitation in answering the question in the affirmative. All knowledge is interrelated; in times of stress the most scientific nation has a big advantage. Surely a society like ours, where year in and year out some of the most important advances in medicine have first come to the light of day, should carry on through the present unpleasantness. Moreover, with so many of our colleagues scattered over the 7 seas, a big responsibility accrues to us who are left to keep the home fires burning in respect to clinical investigation.

It is perhaps a presumptive symptom of an oncoming intellectual menopause,-indeed, one might say it is evidence of a Young Turk becoming an Old Turk,-when one endeavours to lay down certain precepts for success in a field. It is probably fortunate that no one follows such precepts anyway, that each prefers to learn his own way, though this be the hard way. Be all this as it may, as I look around at those of our colleagues who have attained success in the field of clinical investigation and analyze what methods they have used, I see certain recommendations or "Do's" which may be worth jotting down; furthermore, as I look further, especially into my own past, I see certain "Do-not's" which may be equally worthwhile jotting down as practices to be avoided. I won't attempt to define "success." I do not necessarily mean academic recognition; I do not necessarily mean self-satisfaction; I just mean success.

First let me insert a short digression on what is meant by "clinical investigation." I recently had the pleasure of sitting in on a discussion in which our editor-in-chief, Dr. James L. Gamble, deplored the term "sub-clinical" used in the sense of "pre-symptomatic"; Dr. Chester S. Keefer, who was present, enlarged on this theme and pointed out that "clinical" is derived from the Greek word "klinikos" meaning bed, and that "sub-clinical" (a Latin-Greek hybrid) literally means "under-the-bed." Since animals do not sleep in beds it is quite clear that "clinical investigation" has primarily to do with the investigation of sick people, and is concerned only secondarily, if at all, with sick laboratory animals. But more of that in a minute.
I think of a clinical investigator as one trying to ride two horses,-attempting to be an investigator and a clinician at one and the same time. Whereas such an equestrian manoeuver is usually considered a bad policy, in this case, probably because of two considerations in particular, experience has shown that it is a very fruitful pastime. In the first place, the ultimate goal of most investigation is to find something of benefit to the human race; where, other than by the bedside of sick patients, could one find so many suggestions of things to be investigated? Secondly, in many instances, nature has arranged an experiment in a sick individual and partly completed it; all that is needed are the eyes of the clinician to make certain observations, and the background of the investigator to plan other observations and interpret them.

This rider of two horses, however, must remember that there are two horses; he must avoid the danger on one side that he, as a clinician, be swamped with patients and the equal danger on the other side that he, as an investigator, be segregated entirely from the bedside. In his laboratory, necessarily easily accessible to the wards, his clinical half will be constantly interrupted by such messages as that Mr. Humpty-Dumpty has had a big fall. As a result, his investigative half will find that he cannot compete with the straight non-clinical investigators as regards animal or smoked-drum experiments. To answer a vital question, where such technics are necessary, it is often preferable that he persuade one of his nonclinical colleagues to carry out the observations. You can all look around you and see many examples where a good clinician has gone to the laboratory to get the answer to a question and has gotten it,- -more power to him. All I am trying to say is that, if you have acquired the difficult technic of being a fair clinician, you had better use this technic in your clinical investigation.

Let me add one additional point: an intelligent patient, private or otherwise, to whom you have taken the trouble to explain the nature of the investigation, makes the best laboratory animal.

I would not feel quite right addressing this Society without presenting one of what Dr. James $\mathrm{H}$. Means has termed, because of the arrows, my St. Sebastian diagrams. Accordingly, I have arranged one such (Figure 1), depicting the "Do's" and the "Do-not's" which one must pass by in climbing the road which leads to the Castle of Success in Clinical Investigation. You will note that the road is formed by the amalgamation of two paths, 


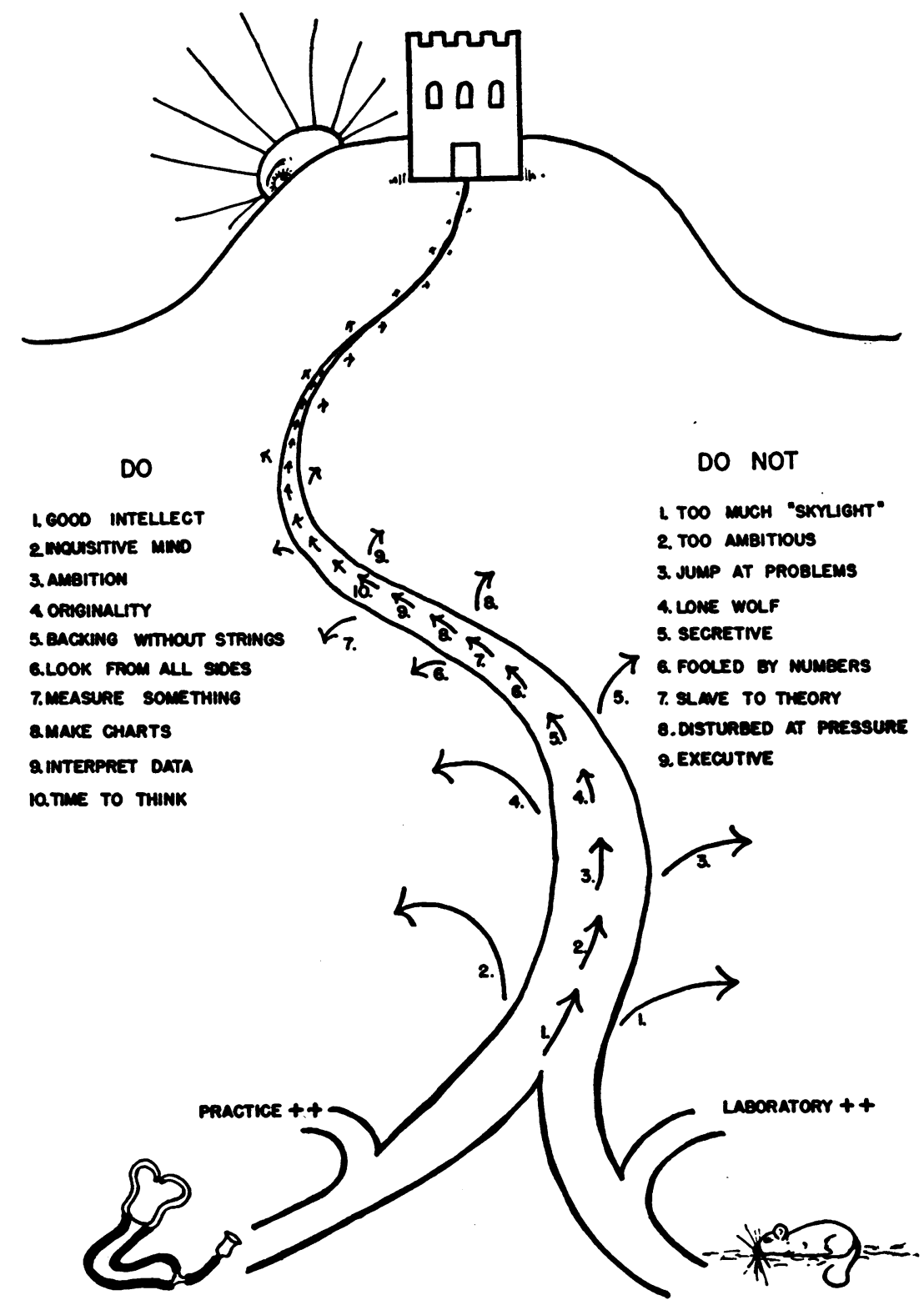

Fig. 1. The "Do's" and "Do-nots" Along the Road Leading to the Castle of Success in Clinical Investigation.

one representing the clinical side and the other the laboratory side.

"Do" No. 1. Do be born with a good intellect, not necessarily the best of intellects. Oliver Wendell Holmes divided minds into "one-story intellects, two-story intellects, and three-story intellects with skylights." "All fact-collectors," he noted, "who have no aims beyond their facts, are one-story men. Two-story men compare, reason, generalize, using the labors of fact-collectors as well as their own. Three-story men idealize, imagine, predict; their best illumination comes from above through the skylight." One sees the same types among clinical investigators; all three have their places. We all know the data collectors, who fill the literature with amorphous data but do not tell us what the data mean. We can look around us, too, and see a few three-story intellects with skylights. One such was the late Dr. L. J. Henderson. It is often unnecessary for the highest intellects to do any collecting of data; they can often take somebody else's published data and arrive at some important new truth. This requires no laboratory animals, no complicated chemical determinations. In this connection, 
Dr. Read Ellsworth once cited an excellent example. Throughout nearly an entire lifetime, Tycho Brahe sat in his laboratory assiduously observing and recording, night after night, the precise position of the planets and stars. Kepler, a calculator par excellence, seized upon this amorphous mass of figures and out of the confusion there emerged three great laws of the movement of the planets. This fortuitous combination of Tycho Brahe's patient accuracy with Kepler's ability to reason and calculate, the one-story intellect with the three-, turned out to be extremely significant for Science.

"Do-not" No. 1. But, do not have your skylights too widely open; install some venetian blinds. There is a real danger in having more mind than matter, as Dr. $\mathrm{E}$. Cowles Andrus aptly put it, - of having so many ideas that one flits from problem to problem without ever completing anything. After perhaps ten years of flitting, our intellectual genius wakes up to find that a one-story intellect friend, who has had but one thought, has proved it beyond all manner of doubt while he himself has had innumerable brilliant theories all of which still remain theories.

"Do" No. 2. Do develop an inquisitive mind. Some people can look at a problem and never see that there is a problem; in the words of the late Professor Jacob Erdheim, with whom I spent a very profitable year, "Die Augen sind gut, aber sie schauen nicht an." Professor Erdheim was constantly asking himself, and surprisingly often answering the question: "Wass is die Ursache?" If you don't ask the questions, you won't find the answers. For example, most doctors would look at a patient with Paget's disease with bowing in one leg and not the other and would fail to ask themselves why the bowed leg is long enough to reach the ground,-in fact is as long if not longer than the other leg. If one asks the question, as did Professor Schmorl of Dresden, and looks for the answer, the explanation is simple and quite interesting (1).

"Do" No. 3. Do be ambitious. Ambition breeds energy. Clinical investigation requires sweat, if not blood and tears!

"Do-not" No. 2. Do not be too ambitious. Too-muchambition breeds jealousy; jealousy breeds unhappiness. At any one time, credit seldom goes where credit is due. When the partition of credit leaves our over-ambitious colleague on the short end, he boils. Let our unhappy colleague whose work has produced important negative evidence keep his sense of humor; his more discerning colleagues recognize that, in the labyrinth of Science, to point out that one door after another is not the right one is of great help to those who follow. With many intricate problems, it is necessary first to demonstrate that two and two do not make five or six or seven, before the fellow who gets all the credit comes along and discovers that they make four. In short, let our colleague remember that, in the long run, credit does go where credit is due.

"Do" No. 4. Do have that something which, for want of a better term, I will designate "originality." One can possess the best of intellects and still fall down in investigation because one is completely lacking in this. I do not think that the prospective investigator, or his adviser, can tell without his actually trying whether this important but intangible quality is present. I am not sure that one cannot acquire it. I rather think that a well-developed ability to correlate ideas may almost take the place of what I am talking about.

If one makes it a practice every time one hears of a new and interesting fact to ask himself if this fact has any bearing at all on his own particular pet problem, it is surprising to find how often it may have. For example, one hears that phosphatase is found in the kidneys. The parathyroidologist asks himself: "Does this have anything to do with parathyroid function?" "Well," he muses, "the parathyroids have something to do with excretion of phosphates in the urine. Phosphatase has something to do with getting phosphates across membranes. Ergo, does the parathyroid hormone influence the amount of phosphatase in the kidneys?" 1 The final question may have the appearance of an original thought when as a matter of fact it is the logical outcome of a process of correlation,-of putting a few known facts in juxtaposition as it were.

"Do" No. 5. Do obtain a backing, financial and otherwise (Don't ask me where!), which leaves you absolutely free to pursue whatever project seems most promising. The man and not the project should be endowed. His natural interest may take him from calcium to parathyroids, to bone disease, to kidney stones, to urinary infections; from calcium to bone disease, to gonadal hormones, to ovarian dysfunction, to amenorrhea, to hypothalamus, to psychosomatic medicine, etc., etc. Too often promising work in one field is interrupted because somebody with a bank account wants to know the answer to some specific problem such as the cure for cancer, the cause of otosclerosis, or what have you. New knowledge, be it where it may, is of importance, and the cure for cancer may come from somebody who is working in a field apparently entirely unrelated to cancer. I am told that the Russians are encouraging scientific research of any kind. Certainly from the $1940-41$ programs of the Biochemical Society of London one would never suspect that England was in a life-or-death struggle.

"Do" No. 6. Do look at your problem from all points of view; don't get too close to it at first, but cover the entire field with a low-power lens; then when some point of interest presents itself turn down on that with a highpower lens.

Most problems in clinical medicine are best approached from several directions. Take the subject of hyperparathyroidism. The clinical side tells us that some cases have such and such symptoms in relation to their skele-

1 This series of questions was stimulated by the interesting investigations of Dr. Charles D. Kochakian of Rochester, N. Y. He went through the same process of reasoning and is now in the process of obtaining the answer to the final question. 
tons, that others have no skeletal symptoms, that kidney stones and polyuria are common, whether or not skeletal symptoms are present, etc. The morbid anatomy of the bones shows us that there is a very rapid turn-over of bone tissue in those cases that have bone disease and that there is absolutely nothing abnormal going on in the bones in those cases that do not have bone disease. The chemical side tells us that the level of serum calcium is high and the level of serum phosphorus is low whether there is bone disease or not, but that the serum phosphatase level is high only in those cases with bone disease, etc. The metabolic studies tell us that the urinary calcium and phosphorus excretions are high in all cases whether they have bone disease or not, that a patient need not be in negative calcium balance if the calcium intake is sufficiently high, etc. But the combined approach, which takes in clinical aspects, morbid anatomy, chemical findings, and metabolic observations, leaves us with some idea what the disease is all about.

"Do-not" No. 3. Do not jump at the first problem which presents itself. When I first started investigation, I thought that it would be virtually impossible to find a problem which had escaped the attention of eager investigators since the beginning of time and which gave any hope of being soluble. As a matter of fact, there are good problems everywhere. Remember, it is much easier to start an experiment than it is to finish one. This is one lesson that I have never been able to learn; I hate to think of the grief I would have been spared had I learned to count ten before launching into a new problem.

There are certain reservations, however, which should be made to the above. In clinical investigation it is often necessary to start a new problem on the spur of the moment in order to employ some unusual opportunity produced by disease. A reverse reservation is that certain problems should never have been started. And here it should be sadly but firmly recognized that it is a mistake to go on and on in the hope of salvaging something rather than to scrap the whole wretched business.

"Do-not" No. 4. Do not be a lone-wolf investigator, - one who never discusses his results or methods of approach with anybody else, who never invites criticism. Most problems are sufficiently complex that they require for their solution the combined efforts of a group. This group need not necessarily be set up as a group under one chief; one investigator working by himself in his own laboratory is not a lone-wolf investigator if he frequently seeks the advice and help of his colleagues in other laboratories-if he makes it a practice to attend the "May meetings" in Atlantic City, and puts in some good work comparing notes on the boardwalk.

"Do-not" No. 5. Do not be secretive. Talk about your work without fear that somebody will publish before you. The danger one runs of having intellectual property pirated is far offset by the suggestions one receives from colleagues. I recall waiting for the report of certain experiments, the details of which were kept secret; when the report finally came out it was full of loopholes which might have been eradicated had the authors discussed their findings with others. I am quite sure that nine times out of ten, when an investigator believes that his work has been pirated, this is not the case. Knowledge accrues usually in a logical manner. The next step comes when the stage has been set. It is not surprising when two or three laboratories arrive at the same answer at the same time. Material which is rushed into print for the sake of priority is usually from the hands of one-story intellects, trying to beat other one-story intellects in reporting some perfectly obvious experiment.

Furthermore, half the fun of investigation is talking about it. If one talks only about the experiments one has completed and proved, one will have relatively little conversation; if one talks about all the theories one has not yet proved, the sky's the limit.

"Do" No. 7. Do measure something. I need not remind you gentlemen that science is based on measurements. Indeed this is so well-understood today that at times one wonders whether the pendulum has not swung too far from the state of affairs in the Middle Ages. Then it was all metaphysics and no measurements; now it is all measurements and no metaphysics. Perhaps a dash of the latter would be a useful condiment.

The real problem is what things to measure, how to measure them, and especially what control measurements to make. I have no special thoughts on this subject other than one minor point. In general, one should make the measurements to answer the problem; not look for a problem which will be an excuse for carrying out certain complex measurements. This assertion must of course be qualified. An interesting new investigative tool is discovered (e.g., isotopes) ; it is certainly intelligent to do a bit of prospecting with this new tool in order to determine where in the investigative field it will produce additional information. Some investigators are born gadgeteers; they love complicated set-ups. Some of the best advances, however, have been made with very simple measurements. The determination of the weight of hair produced in an axilla, expressed in grams per axilla per week, may give you the same information, mirabile dictu, as an assay of the urinary excretion of that steroid which has a ketone group on the seventeenth carbon atom.

"Do-not" No. 6. Do not be fooled by figures. Granted that figures do not lie and that liars figure, the fact remains that figures can give you a false sense of security. One can prove statistically that one set of figures is significantly different from another set; the question remains as to why they are different. No matter how careful you are, in almost any experiment another variable than the one you are studying creeps in and may be the cause of the changes observed. In studies on calcium metabolism, for example, the unaccounted for variable may be the amount of ultraviolet light in the atmosphere or the amount of calcium swallowed with the tooth powder.

"Do" No. 8. Do where possible arrange your data in chart form. This has long been a recognized practice with certain variables,-especially temperature, pulse, and respiration. The importance of charting was first brought home to me at Johns Hopkins where Dr. Warfield T. 
Longcope has his students chart any variable that can be charted. I remember particularly a case of undulant fever with intermittent hydrarthrosis where Dr. Benjamin M. Baker, Jr. charted the circumference of each knee and found that the right knee was swollen when the left knee was down and vice versa in perfectly regular 7-day cycles (2). These are very interesting observations which probably would never have been made had the data been entered in the record as so many separate notations. Incidentally, these observations of Dr. Baker have been in the literature now for 15 years. It is about time some inquisitive mind put forth a theory as to why one knee was swollen when the other was down and why the cycles were exactly 7 days. I can hear Erdheim's spirit mumble: "Wass is die Ursache?"

In the preparation of data for publication, I also believe a chart is extremely helpful to the reader; it should not, however, replace tables of data, which are much more convenient for the three-story intellects who will usually wish to make some recalculations.

"Do" No. 9. Do develop a theory or, at the very least, do try to correlate your work with the sum total of human knowledge. Don't burden this weary world with data without giving a hint as to the reason why they were collected and what they mean. As some of you know, I am one of those who believe that any theory is better than none at all. For example, I am not happy with the statement that, on administration of parathyroid hormone, the serum calcium rises and the serum phosphorus falls. I want to know whether the serum calcium rises because the serum phosphorus falls or whether the serum phospohrus falls because the serum calcium rises, and what is more, I do not want the authors to straddle the issue.

The purpose of a theory is twofold: (a) to give you something upon which you can hang the facts, and (b) to give yourself and your colleagues something to tear down and replace with a better version. By "theory," you will note, I really mean "working hypothesis."

"Do-not" No. 7. Do not be a slave to your theory. When new facts present themselves which require a change in the theory, change the theory. Do not feel hurt if somebody else changes it for you. Do feel hurt if your facts are wrong; not if your theories are wrong.

"Do-not" No. 8. Do not be too disturbed at pressure exerted upon you to produce tangible results, $i$. $\dot{e}$., papers or reports. Often one hears lamentations over the "constant pressure to produce something." Such pressure has its obvious faults, but may be a blessing in disguise. Often, there is a certain amount of inertia about actually working up one's data and yet, not infrequently one's best thoughts do not come until one attempts to put down one's findings in black and white. Alas, it is too often only then that one really finds the shortcomings of one's data! Furthermore, if one waits a period of years with the expectation of getting out a magnus opus when the work is completed, one should remember that worthwhile work is seldom completed. There is always just one more answer which the inquiring mind would like to have. Finally, the data become so voluminous that the mind shrinks from assembling them.

"Do-not" No. 9. See to it that you do not wake up some fine morning in an executive job. Do not show too much administrative ability. The first time you are asked to serve on a committee, be anything but efficient. Never make the mistake of proposing some new reform; you are apt to be chosen as a committee of one to put said reform through. The desk of the good executive should be clear; that of an investigator should be littered. Questions will constantly come up which cannot be immediately settled and filed away. They must be pondered over. Whatever else you do, do not become a Professor of Medicine or the head of a department. Let me make it clear that I do not deprecate the good executive. I realize that it may be commendable for a man to sacrifice his own investigative career to direct the investigations of others. He may climb to bigger and better castles but his chances of arriving at the castle under discussion lessen with his executive duties. I appreciate too that some men manage to continue their investigative work in spite of the fact that they become executives. I am cognizant that the top academic jobs are mostly executive and must be filled by the top academic men. I am aware of the fallacy of the oftenmade suggestion that the administrative jobs be filled by men with executive and not necessarily academic ability. I have little constructive criticism to offer at this point. An obvious suggestion is to find some Lady Bountiful to endow some purely research associate professorships in clinical departments. But I am not sure that this would work; there is such a thing as being too sheltered from the world of responsibility. Certainly such professorships should not be relieved of the responsibility and stimulation of teaching and care of patients.

There is another more subtle way to find oneself eased into an executive job. You start, shall we say, as a young investigator apprenticed to a seasoned veteran; perhaps a small corner of the laboratory is allotted to you where you can carry out your measurements. The first step forward comes perhaps when you get sufficient money from some fund to hire a technician. Then your work may attract the attention of some bright young investigator who attaches himself to you; then come more funds, more technicians, and more assistants. All the financial grants require yearly reports; data are collected which have to be gone over; papers have to be written; speeches have to be made; teaching has to be taught; pretty soon one is less and less in the laboratory and more and more at his desk. You are caught-the fun of directly carrying on investigation is not for you;-you are an executive.

"Do" No. 10. Do try to reserve some time during the day when you can do some unadulterated thinking. If you salvage a few minutes, you will be doing better than most. Some people, the peripatetic school, do their thinking while walking around; they bump into you in the corridors and get the reputation of being absentminded. Some think while they are driving their auto- 
mobiles; this has its disadvantages to the public at large. Some get a few minutes while walking to and from their work; this is excellent. But most seize a few relaxed moments while taking the morning hot shower; this may lead to a hot water shortage if some particularly difficult concept has to be thought through. Let thinking come where it will, the important thing is that time be found to put the new facts which have come before one's sensorium in juxtaposition to the old problems.

\section{LAST LAP}

Well, you do the "Do's" and you do not do the "DoNot's"; you arrive at the door of the Castle of Success. You still need the key to open the door. The key stands for the personal equation. "But personality does not count in pure science," you say. That may be true, but Clinical Investigation is not a pure science.

\section{BIBLIOGRAPHY}

i. Reifenstein, E. C., Jr., and Albright, F., Paget's disease: a concept as to its pathologic physiology, and the importance of this in the complications arising from fracture and immobilization. New England J. Med. (in press).

2. Baker, B. M., Jr., Undulant fever presenting the clinical syndrome of intermittent hydrathrosis. Arch. Int. Med., 1929, 44, 128.

The Mechanism of Pyridoxine-Deficiency Anemia. By George Cartwright (by invitation) and Maxwell M. WinTrobe, Salt Lake City, Utah.

Pyridoxine deficiency has been studied in swine with special reference to the anemia and its relationship to protein metabolism. The anemia is microcytic and hypochromic in type and is accompanied by an elevated serum iron, hemosiderosis of the tissues, and bone marrow hyperplasia. Nevertheless studies on serum bilirubin, reticulocytes, icteric index, and urobilinogen excretion showed that there is no increase of blood destruction. The anemia appears to be due to faulty synthesis of hemoglobin. The ferremia and hemosiderosis are prevented by restricting the dietary intake of iron. This indicates that the hemosiderosis is caused by the continued retention of iron at a time when its utilization for hemoglobin formation is at a minimum.

The place in hemoglobin formation at which pyridoxine exerts its action was sought by feeding a variety of substances, including chlorophyll, and hemin, to pyridoxine-deficient animals. The metabolism of tryptophane is disturbed in pyridoxine deficiency and three products of tryptophane metabolism are found in increased quantities in the urine of deficient animals. The significance of the finding of certain urinary pigments in cases of nutritional deficiency is discussed in relation to these observations and the factors concerned in hemoglobin formation are considered.
Panmyeloid Arrest in Rats Produced by a Purified Diet Containing Sulfaguanidine and Corrected by Liver or Yeast Extracts.1 By Frank H. Bethell and (by invitation) Marion E. Swendseid, and RAY H. RosenMAN, Ann Arbor, Mich.

Young mature rats maintained on a vitamin-free diet containing 2 per cent sulfaguanidine and supplemented by crystalline vitamins develop progressive leukopenia, granulocytopenia, thrombocytopenia, and normocytic anemia. It has been shown that these changes are the apparent result of a conditioned nutritional deficiency induced by the bacteriostatic effect in the intestine of the sulfanilamide derivative. The lowered values may be prevented or corrected by extracts of liver or yeast containing "folic" acid (vitamin Bc).

At the maximum observed developmental arrest, the marrow total nucleated cell count is but slightly less than that of normal rats. However, the majority of the marrow cells in the affected animals are undifferentiated primitive forms, with relative increases in myeloblasts and early erythroblasts. Myelocytes, late erythroblasts, and megakaryocytes practically disappear.

By means of marrow differential counts, performed on successive days after the administration of such liver or yeast extracts, it has been possible to determine the change in relative numbers of cells at each stage of development of the granulocyte and erythrocyte series. A close parallelism in the maturation of the members of the two cellular series is demonstrated. These observations provide evidence in support of the theory of a common stem cell origin of all blood cells developing in the marrow of the rat.

Studies on Increased Coagulability of the Blood. By Theo. R. Waugh and D. W. Rudick (introduced by Donald McEachern), Montreal, Canada.

The need for a test to demonstrate the presence of an increased coagulability of the blood has been accentuated by the recent interest in thrombosis and the use of dicoumarol.

Such a test using heparin as an anticoagulant is here presented. By thus slowing the process, finer analysis of any abnormalities, particularly acceleration, is made possible.

The result is expressed as a graph and experimental evidence along with the theoretical consideration of the mode of action of heparin indicates that this method may be a measure of the relative thromboplastic content of the blood.

Studies employing this test demonstrate a small range of variability in normal individuals and an increased coagulability, (1) during uncomplicated bed-rest, (2) following operative procedures, and (3) in the presence of acute infections.

1 The liver extract was supplied by the Wilson Laboratories. The yeast extract was supplied by Parke, Davis and Company and contained 85 gammas of vitamin Be per ml. 
Response of Cardiovascular System of Normal Subjects to Acute Blood Loss.1 By Eugene A. Stead, Jr., and (by invitation) JAMES V. WARren, EMMeTt S. BraNnon, and Arthur J. Merrill, Atlanta, Ga.

The removal of 300 to $900 \mathrm{ml}$. of blood was performed 10 times on 8 subjects in the basal state. Quantitative studies of the circulation were made before and after bleeding. A catheter was introduced into the right auricle, using the technic of Cournand and Ranges. The auricular pressure and samples of mixed venous blood for analysis of oxygen content were obtained by this means. A special inlying needle was placed in the femoral artery and the arterial pressure was recorded optically by the method of Hamilton and samples of blood obtained for analysis of oxygen content. The oxygen consumption was measured by the analysis of the expired air. From these data, the cardiac output was calculated, using the Fick principle.

In 5 experiments, the subjects appeared to be relaxed and the observations before bleeding were in the range of those of our normal basal subjects. The cardiac index (cardiac output in liters per minute per square meter of body surface) varied from 2.3 to 3.4 . In 5 experiments, the subjects were anxious and the control observations showed evidence of a hyperactive circulation, the cardiac index ranging from 3.9 to 6.0 . The high cardiac index was accompanied by only a slight rise in oxygen consumption. There was no observable difference in the response of these two groups to bleeding. The most striking change was a fall in auricular pressure, which ranged from 20 to $50 \mathrm{~mm}$. of $\mathrm{H}_{2} \mathrm{O}$. Oxygen consumption, cardiac output, arteriovenous oxygen difference, mean arterial pressure, and calculated peripheral resistance showed no consistent changes in the 7 experiments in which circulatory collapse did not develop. In 4 subjects, the blood was returned. The auricular pressure rose, but the cardiac output showed no change in the 3 instances in which it was measured. From the above observations it may be concluded: (1) Anxiety may cause a 100 per cent increase in cardiac output above the basal state. This may occur without a striking increase in oxygen consumption. (2) The auricular pressure may be lowered considerably without affecting the cardiac output and without inducing peripheral vasoconstriction. (3) Anxious subjects may maintain an output far above the basal level in spite of a decrease in auricular pressure. The mechanism by which the cardiac output is maintained in spite of a falling auricular pressure has not been determined.

In 3 experiments, primary shock or circulatory collapse occurred shortly after the removal of the blood. in each instance, the subjects complained of epigastric discomfort, nausea, faintness, feeling of heat, and sweating. Consciousness was not lost. They became pale and perspired freely. The heart rate slowed, the mean arterial pressure fell precipitously to approximately one-half of the control value, the auricular pressure did not fall

1 Work done under contract with the Office of Scientific Research and Development. further, and may have risen slightly. The cardiac output was unchanged. Therefore, the calculated total peripheral resistance fell strikingly, indicating arteriolar dilatation. Two of these reactions occurred in one subject. On the first occasion, the patient was anxious and the control cardiac index was 5.1. At the height of the circulatory collapse, the index was 4.9. Four months later, when the experiment was repeated, he was calm and the control cardiac index was 3.4. At the height of the circulatory collapse, it was 3.3. It is to be noted that the signs and symptoms of primary shock appeared at two greatly different levels of cardiac output.

It may be concluded that: (1) A fall in cardiac output is not necessary to produce the manifestations of primary shock. (2) The fall in arterial pressure is caused by a primary decrease in peripheral resistance rather than by secondary response to a decrease in venous return.

'Experimental Hypertension from Section of Moderator Nerves: The Relationship of the Acute Pressor Response to the Development and Course of 'Chronic Hypertension. 1 By Caroline Bedell Thomas, Baltimore, Md.

The moderator nerves of 10 dogs were sectioned at successive operations. Arterial pressures and pulse were recorded by the Hamilton method both with animals unanesthetized and during operations. Inconstant rise and increased lability of pressure first appeared after the third operation, regardless of the order of nerve section. Immediately after cutting the fourth moderator nerve, arterial pressure rose abruptly but soon fell again, and was usually normal a few hours later.

Well marked hypertension appeared 1 to 6 days after the fourth operation, and in some animals it gradually increased in subsequent weeks. Arterial pressures of $425 / 222$ have been recorded. Marked tachycardia and lability of pressure and pulse were found. There was close correlation between heart rate and arterial pressure, indicating the importance of increased cardiac output in this form of hypertension.

Intravenous injection of epinephrin and angiotonin was carried out before and after hypertension had been produced; the increased vasoconstriction produced by the hypertension did not decrease the height of the pressor response to either agent.

Chronic hypertension was observed to persist for 5 years. No pathological lesions attributable to the hypertension were found, with the possible exception of changes in the juxtaglomerular apparatus, which is still under investigation.

Orthostatic Hypotension and Orthostatic Tachycardia in Patients with Diabetic Neuropathy. By R. WAYNE Rundles (introduced by Cyrus C. Sturgis), Ann Arbor, Mich.

Observations on 125 patients with diabetic neuropathy revealed orthostatic circulatory abnormalities in 8 . Five

1 Supported by a grant from the Commonwealth Fund for the study of essential hypertension. 
patients had attacks of vertigo or syncope when standing, and a fall of $50 \mathrm{~mm}$. $\mathrm{Hg}$ or more in the systolic blood pressure when changing from the supine to the erect position. Prompt syncope followed forceful expiration (Flack test). Oliguria and diminished renal function when standing were demonstrated. A young male with a neuropathic joint destruction and a patient with pseudotabes showed smaller postural blood pressure changes but pronounced orthostatic tachycardia. One patient had an average blood pressure when supine of 178/96 (pulse 102) and when standing of 120/80 (pulse 120). Lack of cardiac acceleration was not observed.

These patients all had a common background of several years of poorly managed or neglected diabetes, finally complicated by severe peripheral neuropathy. The majority had, in addition, abnormal pupillary reactions (Argyll Robertson type in 3 cases without evidence of neurosyphilis), chronic or recurrent diarrhea with roentgen evidence of grossly disturbed gastro-intestinal motility, impotence, and atonic bladder paralysis.

Peripheral loss of sweating was shown by sweating tests and vasomotor paralysis by skin temperature studies. Peripheral degeneration of sympathetic nerves appeared to be an important factor in the etiology of the orthostatic circulatory syndrome.

\section{Observations on Renal Venous Blood in Normal Un-} anesthetized Subjects and Patients with Severe Congestive Heart Failure. ${ }^{1}$ By James V. WARREN, Arthur J. Merrill, and Emmett S. Brannon (introduced by Charles A. Doan, Columbus, Ohio), Atlanta, Ga.

The present concepts of human renal physiology are based upon somewhat unstable tenets because of the difficulty in obtaining blood from persons immediately before and after its passage through the kidney. The widely used clearance techniques for determining renal blood flow are based upon the assumption that the test substance used is completely removed from the blood during one circulation through the active renal tissue. Arterial blood may be obtained with relative ease from a peripheral vessel because its composition is the same throughout the body, but obtaining venous blood as it leaves the kidney has presented the major problem. The method described here has enabled us to obtain blood directly from the renal vein in the unanesthetized resting subject.

The method is essentially a modification of the technic of right auricular catheterization introduced by Forssman in 1929 and recently extensively utilized by Cournand and his colleagues. A long radiopaque ureteral catheter is passed up the venous system from the antecubital vein into the right auricle and thence via the inferior vena cava to either renal vein. By fluoroscopy, the catheter is seen to pass laterally from the vena cava in the region of the renal pedicle, and to

1 Work done under contract with the Office of Scientific Research and Development. move with the respiratory excursion of the kidney. The position of the catheter may be further checked by intravenous pyelography. Most conclusive evidence that the catheter is in the renal vein is obtained from the comparison of arterial and renal venous blood. The renal venous blood of normal subjects has a high oxygen content and is therefore brighter red than the mixed venous blood from the auricle. As the kidney, removes the majority of sodium p-amino hippurate when its concentration in the plasma is low, there is a striking difference in the concentration of this substance in the arterial and renal venous blood following injection of sodium p-amino hippurate into the antecubital vein.

Simultaneous samples of the renal venous and arterial blood were obtained for study of the extraction of oxygen and sodium p-amino hippurate by the kidney. Immediately after obtaining the renal vein sample, the catheter was withdrawn to the auricle and a cardiac output determination was carried out, utilizing the Fick principle.

Observations have been made on patients without apparent renal disease. Several had considerable anemia, as reflected in the oxygen content of the arterial blood. In the 8 cases where it was determined, the renal $\mathrm{A}-\mathrm{V}$ oxygen difference varied from 1.9 to 2.8 volumes per cent, while in the same subjects the difference in oxygen content between the mixed venous and arterial blood ranged from 3.4 to 6.1 volumes per cent. The cardiac index in these subjects ranged from 2.3 to 3.8 . With arterial plasma hippurate levels below $2.5 \mathrm{mgm}$. per cent, the extraction by the kidney averaged 88 per cent.

Observations were made on 2 patients with chronic congestive failure in whom the cardiac output was decreased. The renal arteriovenous oxygen difference in these patients was 5.5 and 6.5 volumes per cent, suggesting the the renal blood flow was decreased. The renal extraction of hippurate by these patients was 82 and 90 per cent complete during a single circulation through the kidney. Determination of the renal blood flow by the usual clearance technic confirmed the fact that the renal blood flow was greatly decreased.

The ease with which renal venous blood can be obtained opens up a new field of study in patients with kidney disease, hypertension, shock, and cardiac failure.

\section{Plasma Volume and "Extravascular Thiocyanate Space" in Pneumococcus Pneumonia. By David D. Rutstern, K. Jefferson Thomson, Daniel M. Tolmach, Whlliam H. Walker, and Robert J. Floody (intro- duced by L. W. Gorham), Albany, N. Y.}

A study of the fluid content of the cardiovascular system and the extracellular space of 46 pneumonia patients was performed.

Plasma volume and "extravascular thiocyanate space" are significantly increased during pneumococcus pneumonia and decrease below normal immediately following recovery. Total blood volume calculated from the plasma volume and venous hematocrit, and total available fluid showed similar changes during pneumonia. Clinically, these patients appeared dehydrated. 
Plasma volume and "extravascular thiocyanate space" of fatal cases are significantly lower than similar measurements made on recovered patients during pneumonia.

Venous hematocrit, red blood cell count, and hemoglobin are unchanged during pneumonia. Therefore, the mean corpuscular volume, the mean corpuscular hemoglobin, and the mean corpuscular hemoglobin concentration are also unchanged during pneumonia.

The findings of this study indicate that the total circulating solutes are diminished less than would be indicated by the measurement of the concentration of such solutes. They also offer an explanation for the precipitation of cardiac failure during pneumonia in patients with heart disease and suggest the need for care in the administration of fluids to cardiac patients suffering from pneumonia.

Non-Hemolytic Streptococci in Primary Atypical Pneumonia. ${ }^{1}{ }^{2}$ By L. Thomas, G. S. MIrick, E. C. Curnen, JR., J. E. ZIeGler, JR., (by invitation), and F. L. Horsfall, JR., 3 New York, N. Y.

A single serological type of non-hemolytic streptococcus was isolated from the lung tissues of 6 of 8 fatal cases and from the sputa of 50 of 91 patients with primary atypical pneumonia. Seventy per cent of 186 patients with this illness developed specific agglutinins against this bacterium during convalescence. Less than 3 per cent of sera from normal persons and patients with other diseases showed similar agglutinins. Specific precipitins against a polysaccharide extracted from this streptococcus appeared during convalescence.

Homologous immune rabbit serum specifically agglutinated this bacterium, gave precipitates with the polysaccharide, and caused capsular swelling. Selected high titer human convalescent sera also gave a positive quellung reaction.

Cultural and biological studies on all strains of this micro-organism isolated yielded strikingly constant results which served to distinguish it from other nonhemolytic streptococci. Antigenically, it was related to but not identical with Type I Streptococcus salivarius (Sherman). It was avirulent for all mammalian species tested but was pathogenic for young chick embryos. The bacterium was resistant to sulfonamides but was susceptible to penicillin.

There is as yet no satisfactory explanation for the results obtained with this micro-organism in primary atypical pneumonia.

1 The Bureau of Medicine and Surgery of the U. S. Navy does not necessarily undertake to endorse views and opinions expressed in this abstract.

2 The work described was done under a contract, recommended by the Committee on Medical Research, between the Office of Scientific Research and Development and The Rockefeller Institute for Medical Research.

3 Members of the U. S. Navy Research Unit at the Hospital of The Rockefeller Institute for Medical Research, New York, N. Y.
Pharmacology of Sulfabenamide, a Non-Toxic Fatty Acid Sulfonamide. Prolonged Administration in Cases with Pulmonary Tuberculosis. By RICHARD GUBNER (introduced by J. Hamilton Crawford), Brooklyn, N. $Y$.

Sulfabenamide differs greatly in its pharmacological behavior from other sulfonamides now in clinical use. The linkage of the aliphatic caproic acid with the amino nitrogen of p-aminobenzenesulfonehydroxamide is stable, resisting hydrolysis in vitro and in vivo, the compound remaining conjugated in the body to an average of 80 per cent in both blood and urine. Acetylation, accordingly, does not occur except possibly to a negligible degree. Absorption is very rapid, excretion extremely slow. Following a single 5 gram dose, a blood level of 5 to $7.5 \mathrm{mgm}$. per cent is maintained for several days, falling to half the maximum level after one week. Twothirds the amount ingested as a single dose is excreted in the urine in one week. Blood levels with dosage 4 to 8 grams daily range between 5 to $10 \mathrm{mgm}$. per cent, and even with massive dosage, higher blood levels cannot be attained. Urinary concentrations are approximately ten times the blood level.

No toxic effects have been observed when as much as $\mathbf{2 5}$ grams were given in a 16-hour period, or in protracted administration to several cases with pulmonary tuberculosis, one patient receiving over 2,000 grams over a 16-month period. Sulfabenamide exhibits the same range of therapeutic activity as sulfanilamide against streptococcal infections, and experimental pneumococcal and E-typhi infections. Its lack of toxicity, lipoid solubility, and prolonged retention in the body tissues suggested the possibility of employing the drug in tuberculosis. In 5 cases with advanced bilateral pulmonary tuberculosis, treated with 4 grams of sulfabenamide daily for an average period of 10 months, no deleterious effects of any sort were observed, and an average weight gain of 33 pounds occurred. Concomitant with administration of the drug, sputum became converted to negative in all subjects and roentgenograms showed moderate resolution of pulmonary infiltration. No conclusions are as yet warranted as to the therapeutic efficacy of sulfabenamide in tuberculosis. Preliminary in vitro experiments, employing Long's medium, indicate an inhibitory effect on the growth of the tubercle bacillus in concentrations of $5 \mathrm{mgm}$. per cent and above.

New Preparations for the Treatment of Fungous Infections. In Vitro and In Vivo Experiments with Fatty Acid Salts, Penicillin, and Sodium Sulfathiazole. By Edmund L. Keeney (introduced by Warfield $T$. Longcope), Baltimore, Md.

Sodium or calcium propionate is incorporated in bread dough and cake batter by many large baking companies to inhibit the growth of molds. In a previous report, we have demonstrated that sodium propionate inhibits the growth of pathogenic fungi and is effective in the treatment of superficial fungous infections. 
The fungistatic and fungicidal activities of sodium valerate, sodium caproate, sodium caprylate, sodium caprate, and sodium undecylenate have been determined. These fatty acid salts adjusted to a $\mathrm{pH}$ of 7.4 are equal to, or superior to, sodium propionate adjusted to a $\mathrm{pH}$ of from 5.5 to 7.4. The relative toxicity of these compounds for albino mice is extremely low.

The clinical effectiveness of a 1 per cent sodium undecylenate ointment and a 10 per cent sodium propionate ointment in the treatment of the superficial fungous infections is comparable. Clinical experiments are in progress on the effectiveness of these salts in higher concentrations.

Two patients with cutaneous actinomycosis have been successfully treated by the daily parenteral administration of a 20 per cent solution of sodium propionate.

Albino mice infected with Coccidioides immitis are being treated with the fatty acid salts. The results will be reported.

Penicillin is fungistatic and fungicidal for Actinomyces bovis, but fails to possess such activity for the other pathogenic fungi. The same is true for sodium sulfathiazole.

The Cardiovascular Dynamics in Shock Due to Infection. By A. S. Freedberg and H. Haimovict (by invitation), and H. L. Blumgart, Boston, Mass.

Circulatory failure in infectious disease is not well understood. A study of the cardiovascular dynamics has been made in 70 unanesthetized dogs ( 5 to $14 \mathrm{kgm}$.) following intravenous injection of a purified toxin obtained from rough colonies of Shiga type dysentery bacilli.

In all animals, injection of this toxin resulted in a state of "shock" associated with a marked fall in cardiac output, increased arterio-venous oxygen difference, decreased stroke volume, lowered central venous pressure, decreased oxygen consumption, fall in blood pressure, slowed circulation time, and tachycardia. The circulating plasma volume showed no change in one-third of the experiments and a variable hemoconcentration in the remainder. The relative blood viscosity paralleled these changes.

The sequence of events is as follows: Within 15 to 30 minutes after the injection of the toxin, a marked decrease in minute volume output from 25 to 75 per cent occurred. This is associated with an increased arteriovenous oxygen difference and a concomitant decrease in right auricular pressure. These early phenomena seem to be related to a decreased venous return. The arterial blood pressure was maintained and evidence of hemoconcentration was absent at first. During the succeeding hours, despite subsequent considerable rises in body temperature, the cardiac output persistently decreased. The blood volume changes noted above became manifest. Later changes in blood pressure may be divided into 3. broad groups: a sudden fall after 1 to 2 hours to 40 to $50 \mathrm{~mm}$; a maintained blood pressure for many hours with a subsequent progressive decline; and an initial fall with recovery to the control levels, followed by 2 subsequent decline. The differences between this type of shock and those due to hemorrhage, trauma, and burns are noted.

Bagasse Disease of the Lungs: Clinical and Experimental Aspects. By W. A. Sodeman, and (by invitation) R. L. Pullen, S. S. Pinto, and B. Pearson, New Orleans, La.

Workers breaking bales of bagasse, the product remaining after extraction of sugar from cane, sometimes develop a respiratory illness. Eleven such patients have shown a characteristic clinical picture. Cough and dyspnea occur early, after as little as 3 weeks' exposure. Hemoptysis may be seen. Occasionally, cyanosis is noted. Night sweats, chills, and fever are almost invariably present. On physical examination, chest findings are minimal, but the $x$-ray discloses an extensive miliary mottling. Sputum is scanty and mucoid and bacteriologic examination does not reveal anything of importance. Leukocytosis develops with a shift to the left and, at times, polycythemia is seen. The entire picture clears up in a period of approximately 3 to 4 months.

Others have suggested fungus infection and allergy to bagasse as the cause. In a series of skin tests with various bagasse extracts we have found reactions in controls as well as in patients exposed to bagasse. Lung biopsy from one of our patients has shown bagasse particles in the lung tissue, indicating a type of pneumoconiosis. The lung reaction is a peculiar one which has been studied further by Miller's technic, consisting of the injection of extracts into the peritoneal cavity of the guinea pig. Various fractions of bagasse have been injected to determine the reaction to various chemical fractions, with results indicating the presence of a toxic material in bagasse, the relative unimportance of the silica fraction, and tissue responses of a transient nature, indicating a reversible reaction as seen in the clinical picture of bagasse disease.

Control of Hyperthyroidism with Thiouracil and Continued Remission After Therapy. By E. B. Astwood, Boston, Mass.

Thiouracil ( 0.2 to 0.6 gram daily) was administered to 11 normal and 51 hyperthyroid persons. In 33 cases of primary hyperthyroidism, the basal metabolic rate began to fall in 6 ( 3 to 18) days and was normal in 23 (11 to 46) days. Slower responses were noted in 8 cases which had received iodine, 8 cases of toxic nodular goiter, and 2 cases of acromegaly. The normal individuals were treated for 6 weeks without effect. The latent period was apparently related to the quantity of stored hormone and the rate of its release.

A subsequent maintenance dose of 0.1 to 0.2 gram daily controlled all symptoms and maintained normal metabolic rates. Exophthalmos usually regressed slowly and no instance of malignant progression occurred. Some cases with large diffuse goiter experienced a further enlargement and accentuation of the bruit which later subsided. 
Added iodine in 2 such cases induced a further fall in the metabolic rate and disappearance of the bruit. Four cases exhibited a febrile reaction on the 9th to 11th day.

Treatment was discontinued after 6 to 8 months in 9 cases; in each, the metabolic rate remained normal and to date, 2 to 8 months later, there has been no evidence of a return of the disease.

Serum Iodine and Basal Metabolism of Myxedematous and Euthyroid Subjects Treated with Desiccated Thyroid. By Douglas S. RIGGs, (by invitation), Evelyn B. Man, (by invitation), and Alexander W. WinkLer, New Haven, Conn.

Serum iodine values and basal metabolic rates in 10 myxedematous and in 10 euthyroid subjects have been followed at various levels of thyroid medication. In myxedema, serum iodine and metabolic rate varied directly with the thyroid dose within the limits of zero and 2 grains daily. In contrast, in euthyroid subjects receiving larger doses, the response was much smaller and more irregular, so that frequently an increase in dosage produced no response. Insofar as a response developed, however, the increase in metabolic rate for a given increase in serum iodine was the same in both groups.

In euthyroid subjects, cessation of thyroid medication frequently resulted in transitory subnormal levels of serum iodine without comparable depression of metabolism, suggesting temporary inhibition of normal thyroid activity. Tolerance of euthyroid subjects to amounts of thyroid far in excess of normal production of hormone implies, in addition, inactivation of a large part of the exogenous hormone. Breakdown of exogenous hormonal iodine to inorganic iodine by the thyroid gland itself is suggested.

The Effect of Thyrotropic Hormone in the Collection of Radio-Iodine, Mean Acinar Cell Height, and Gland Weight in the Thyroid of the Chick.* By F. R. Keating, JR., Rulon W. Rawson, and Wendell Peacock (introduced by J. H. Means), Boston, Mass.

Chicks were injected with radio-active iodine having a half life of 8 days and the quantity collected by the thyroid was measured with a Geiger counter. Mean acinar cell height and thyroid weight were determined in other chicks similarly treated. With increasing degrees of stimulation by thyrotropic hormone, there is a progressive increase in collection of radio-iodine by the thyroid until a plateau is reached. This increase parallels that in mean acinar cell height. When the plateau in

\footnotetext{
* From the Institute of Experimental Medicine, The Mayo Foundation Graduate School, University of Minnesota, Rochester, Minnesota (Dr. Keating); the Thyroid Laboratory, Massachusetts General Hospital, Boston, Massachusetts (Dr. Rawson); and the Nuclear Physics Laboratory, Massachusetts Institute of Technology, Cambridge, Massachusetts (Dr. Peacock).
}

collection of radio-iodine is reached, thyroid weights have only begun to increase. When the effects of thyrotropic hormone are plotted against time, the mean acinar cell height increases promptly and definitely in less than 24 hours while the collection of radio-iodine and thyroid weight lag behind about forty-eight hours. The collection of radio-iodine and mean acinar cell height later level off but thyroid weights continue to increase. The collection of radio-iodine by the thyroid thus appears to be proportional to the degree of cellular hypertrophy. An increase in the collection of radio-iodine occurs only after hypertrophy has taken place.

\section{Influence of Fat in Diet on Cholesterol Ester Fatty Acids in Hypothyroid State. By ARILD E. Hansen, Gal- veston, Tex.}

In none of the studies reporting increased values for the serum cholesterol and cholesterol esters in hypothyroidism has the character of the fatty acids involved been investigated. In a detailed study of the serum fatty acids in 3 children with hypothyroidism, we found those in the acetone soluble fraction (in which the choleseterol esters are present) to have higher iodine numbers than did those in the acetone insoluble fraction. This indicated that the fatty acids present as cholesterol esters were highly unsaturated, which was actually demonstrated in one case by enzymatic hydrolysis.

In order to determine whether or not this elevation of the cholesterol esters in hypothyroidism might be dependent upon the availability of highly unsaturated fatty acids (which cannot be synthesized by animals) in the diet, detailed determinations were undertaken of the serum fatty acids in 2 mongrel dogs, one receiving 28 per cent of his calories as fresh lard, the other but 0.16 per cent of his diet as fat. Following thyroidectomy, in the animal receiving fat, there was a distinct rise in the cholesterol esters. The acetone soluble fatty acids were greater in quantity, and their iodine numbers remained relatively high, indicating that, as in human subjects, the cholesterol ester fatty acids involved were highly unsaturated. In the animal on the diet almost devoid of fat, the cholesterol esters actually decreased, and there was no increase in either the total amount or degree of unsaturation of the acetone soluble fraction.

These preliminary findings suggest that the increase in cholesterol ester fatty acids in the hypothyroid state is dependent upon the availability of unsaturated fatty acids in the diet.

Alloxan Diabetes in Rabbits and Rats. By C. CaBell Bailey and Orville T. Bailey (introduced by Howard F. Root), Boston, Mass.

Previous observations showed that injections of alloxan into rabbits caused necrosis of the islets of Langerhans and fatal hypoglycemia.

Believing diabetes inevitable under such conditions if hypoglycemic death could be prevented, 2 rabbits were 
given $200 \mathrm{mgm}$. of alloxan per $\mathrm{kgm}$. of body weight, and protected with concentrated glucose intravenously. Within 36 hours, persistent severe diabetes was present.

Histologic sections, 3 days after diabetes developed, revealed selective necrosis of the pancreatic islets of Langerhans without injury to acini and with only minor changes in other organs. In 2 additional rabbits, killed immediately after diabetes developed, microscopic sections showed some islet cells with hydropic degeneration, others with irreversible changes, some essentially normal, while occasional cells were in the process of mitotic division.

Diabetes in rats is best produced by the subcutaneous injection of $200 \mathrm{mgm}$. of alloxan per $\mathrm{kgm}$. The intravenous and intraperitoneal routes did not prove feasible. Eighteen rabbits and 22 rats with alloxan diabetes have been studied in metabolism cages.

Diabetic cataracts developed in 6 weeks in alloxan diabetic rabbits kept alive with insulin and in 3 months in diabetic rats.

Diabetic acidosis and coma have been produced in both alloxan rabbits and rats.

Some Metabolic Aspects of Damage and Convalescence. By J. S. L. Browne, Victor Schenker, and J. A. F. Stevenson, Montreal, Canada.

In healthy adult men after burns, fractures, wounds, operations, etc., there occurs a negative nitrogen balance. This lasts for from 5 to 45 days in the cases studied, depending on the nature and severity of the trauma and on the individual reaction of the patient. At the height of this period of negative nitrogen balance, oral intake of protein up to about 100 grams (2000 cals.) per day is followed on the same day by the excretion of practically the entire nitrogen content of the protein as urea in the urine. The nitrogen of intravenously administered plasma does not appear in the urine in this manner. Preliminary experiments indicate that the nitrogen of intravenously administered protein hydrolysate (Amigen) behaves as does food nitrogen.

The period of negative nitrogen balance is succeeded by one of positive balance. Intercurrent damage such as upper respiratory infection, any increase in fever, etc., is accompanied by an increase in nitrogen output even though the intake may not be altered. This leads to increased negative nitrogen balance. Mild exercise, such as wheeling around in a wheel chair for the first time, or other fatiguing procedures, such as changing a cast, leads during the early part of convalescence to an increased nitrogen output on the same day and to a decrease in positive nitrogen balance or even to a negative balance.

Persons chronically ill before operation also show negative nitrogen balance after operation but differ from healthy adults acutely damaged in that raising the protein intake to moderate levels does not lead to the immediate excretion of all the food nitrogen. These patients can thus be brought into positive nitrogen balance at an earlier period and at a lower level of intake.
Metabolic Studies on the Urinary Excretion of Ketosteroids in Normal Individuals and in Patients with Adrenal Dysfunction and Cancer. By C. P. RHOAds and (by invitation) Konrad Dobriner, New York 21, N. Y., and Seymour Lieberman, B. R. Hill, and Louis F. Fieser, Cambridge 38, Massachusetts.

The determination of the 17-ketosteroid levels in the urines of normal individuals and of patients does not allow for a distinction between the different kinds of steroids excreted nor does it permit the quantitative estimation of the amount of each compound present, both of which may be significant for certain disorders.

Individual urine collections were made and the steroid content studied in a group of normal men and women of different ages, in pregnancy, in patients with adrenal dysfunctions (adrenal hyperplasia, cortical tumor and Cushing's syndrome), and in patients with cancer and leukemia. The neutral fractions obtained from these urines were separated into the ketonic and non-ketonic material. The ketonic components were further divided into their alpha and beta ketonic fractions. The nonketonic material was separated into its alcoholic and nonalcoholic constituents.

In all, 33 different ketosteroids were isolated by systematic quantitative chromatographic analysis of the alpha ketosteroids from the individual urines. Seven of these have been previously described in the literature. Only 9 alpha ketosteroids are constantly found in the urine of normal men and women. Their distribution also follows a consistent pattern. About 60 to 70 per cent of the alpha ketosteroid fraction consists of androsterone and its isomer, alpha hydroxyaetiocholanolone which are present in a ratio of about $1: 1$. The urines of pregnant women and of patients with adrenal hyperplasia and adrenal cortical tumors reveal not only the presence of a great number of ketosteroids not found in normal urine, but also a distinct difference in the pattern of their distribution. In the urine of certain cancer patients, ketosteroids are present which are not found in the urine of normal persons. In others, androsterone is absent or an abnormal ratio of androsterone to aetiocholanolone is found.

The study of the alpha ketosteroid patterns in normal and diseased individuals reveals marked differences in the distribution and types of compounds present. These results give more detailed information with regard to the disturbances of steroid metabolism.

Clinical Actions of Ethylnorsuprarenin.* By M. L. Tainter, W. M. Cameron, L. J. Whitsell, and M. M. HartMan (introduced by T. G. Klumpp), New York, N. $Y$.

The chemical compound 1-(3-4 dihydroxyphenyl)-2amino-1-butanol hydrochloride or ethylnorsuprarenin is

* Supported, in part, by Therapeutic Research Grant 437 of the Council on Pharmacy and Chemistry, American 
a sympathomimetic amine, closely resembling epinephrine in many of its actions. However, it lacks the power to raise systolic blood pressure like epinephrine, but rather lowers the diastolic pressure and increases the pulse rate. Therefore, it causes an increase in pulse pressure, and presumably in the volume flow of blood, without a proportionate rise in cardiac work.

In animals, ethylnorsuprarenin is approximately $1 / 120$ as toxic as epinephrine for fatal effects intravenously, and does not cause excitation of the central nervous system.

In patients, ethylnorsuprarenin may be injected subcutaneously, intramuscularly, or intravenously in doses of from 0.5 to $2.0 \mathrm{mgm}$., with typical effects which appear in from 1 to 5 minutes and persist for from 20 minutes to an hour, depending on the dose and route of administration.

It is effective in the relief of acute asthmatic attacks, giving relief equal to that of epinephrine in doses about one-half larger. This relief is accompanied by fewer and less marked subjective side effects, such a precordial pain, nausea and vomiting, excitation, etc., than might be experienced by the same subjects after equivalent doses of epinephrine.

Accordingly, ethylnorsuprarenin would appear to be useful in the treatment of asthma, and possibly preferable to epinephrine for those patients in whom epinephrine administration is accompanied by undesirable side-actions. Further clinical trials appear to be justified along these and other lines.

Uric Acid Metabolism Studies in Gout. By R. $\mathrm{H}$. FreYberg and (by invitation) W. D. Block and N. GerB, Ann Arbor, Mich.

The effects of different diets, the oral administration of various purines, beef extract, cincophen, sodium salicylate, colchicine, and the intravenous injection of lithium urate were studied in a patient with tophacious gout and in a normal control subject. The amount of uric acid in the blood and 24-hourly urine collections was measured by a recently perfected specific and highly accurate uricase method, as well as the usual silver precipitation, and direct methods, and the results were compared. The silver isolation procedure gave slightly higher values for "uric acid" than did the specific uricase method; but usually it was fairly accurate.

In the gouty patient and control subject, the results were similar. The ingestion of different amounts of purine-free protein, xanthine, uric acid, arginine, and histidine did not significantly change the blood or urine uric acid values. About 25 per cent of the injected lithium urate was accounted for by increase in excretion of uric acid. When caffeine was ingested, the non-

Medical Association, and by grants from the Rockefeller Fluid Research Fund of Stanford University School of Medicine. specific methods showed a great increase in "uric acid", but the specific uricase method showed only slight increase in urine true uric acid with a large increase in other substances giving the color reaction. Ingestion of beef extract caused a substantial increase in the uric acid of blood and urine. Ingestion of adenine sulfate caused an increase in blood and urine uric acid and other substances giving the color reaction-probably other purine degradation products. Guanine caused similar changes but to lesser degree. Cincophen caused considerable increase in the excretion of uric acid and lowered blood uric acid. Sodium salicylates caused an increase in uric acid and in non-uric acid chromogenic substances.

The results of these studies are discussed in regard to reliability of various analytical methods, and in regard to the problem of the metabolic defect characterizing gout.

The Function of the Sweat Glands in the Economy of $\mathrm{NaCl}$ Under Conditions of Hard Work in a Tropical Climate.* By Jerome W. CoNN and (by invitation) Margaret W. Johnston, Ann Arbor, Mich.

Acclimatized men performing hard work (4000 to 4200 cals per 24 hours) in humid heat $\left(85^{\circ} \mathrm{F}\right.$. and 85 per cent humidity) and producing 4 to 9 liters of sweat per 24 hours, remain in $\mathrm{NaCl}$ balance and retain physical 'fitness' on a total dietary intake of $\mathrm{NaCl}$ as low as 5 grams per day. This is accomplished by the ability of the sweat glands to produce a fluid containing progressively lower concentrations of $\mathrm{NaCl}$ as the supply of salt in the diet is diminished and as urinary $\mathrm{NaCl}$ falls off sharply (indicating a need to conserve body salt).

With work, sweat volume, and sweat $\mathrm{NaCl}$ concentration constant, an abrupt change from high to low $\mathrm{NaCl}$ intake produces the following sequence of events: (1) A marked fall in urinary $\mathrm{NaCl}$, (2) followed in 1 to 2 days by a significant fall in sweat $\mathrm{NaCl}$ concentration, (3) a gradual rise in urinary $\mathrm{NaCl}$ until urine plus sweat losses approximate total $\mathrm{NaCl}$ intake, (4) continuation of the newly acquired level of more dilute sweat.

When, under the same conditions of low salt intake and coritinued existence in humid heat, work periods are discontinued for several days (abruptly lowering total sweat volume), there occurs (1) a rapid rise in urinary $\mathrm{NaCl}$, (2) followed by an increase of sweat $\mathrm{NaCl}$ concentration. If increased sweating is now produced by heavy clothing without work, urinary $\mathrm{NaCl}$ falls followed by a decrease in sweat $\mathrm{NaCl}$ concentration.

Under conditions of these experiments, an average diet, containing 10 to 15 grams of $\mathrm{NaCl}$, provides sufficient protection in acclimatized men to make the use of salt supplements unnecessary.

\footnotetext{
* Work done under contract with the Office of Scientific Research and Development.
} 
Studies of Work and Discomfort in Patients with Neurocirculatory Asthenia.* By MANDEL E. CoHEN (by invitation), ROBERT E. JoHNSON (by invitation), Stanley Cobb, William P. Chapman (by invitation), and PAUL D. White, Boston, Mass.

The type of patients studied were men who have complained for many years of dizziness, palpitation, chest discomfort, and dyspnea. This has been associated with inability to do hard work, nervousness, and emotional instability. Control subjects were healthy soldiers.

In studies of ability to do hard work (run on the treadmill at 7 miles per hour, 8.6 degrees grade) the patients (43), when asked to run to exhaustion, ran a much shorter time (mean 79.6 seconds) than did 59 normal control subjects (mean 201.6 seconds). Step tests (20 inch step, 30 steps per minute) in 51 patients gave mean time of 79.1 seconds, compared to mean of 190.3 seconds in 40 control subjects. Lactic acid determinations taken five minutes after end of run on the treadmill revealed a lower level (32 patients, mean 77.1 mgm. per ml. blood) than the normal controls (41 control subjects, mean of $122.7 \mathrm{mgm}$. per $100 \mathrm{ml}$. of blood).

Studies of moderate work (walk on the treadmill at 3.5 miles per hour, 8.6 degrees grade) allow patients to finish the task. Lactic acid determinations taken at the 10th minute of walking yield results almost twice as high in 26 patients compared with 40 normal control subjects (mean in patients, 36.4 ; in controls, $21.6 \mathrm{mgm}$. per $100 \mathrm{ml}$. blood). These results are comparable with similar studies in poorly trained men and in women.

An attempt was made to train a selected group of 23 patients with neurocirculatory asthenia under the direction of an athletic trainer, experienced in this type of training. Half the program involved methods of kindly persuasions; and the other half coercive methods applied by an Army sergeant. Neither method was successful. The subjects were unable or unwilling to undergo the type of training necessary for what the trainer called "real training," i.e., pushing past limits of comfort. The patients complained that uncomfortable symptoms prevented their making the necessary effort.

Studies were made to test the patients' reaction to uncomfortable stimuli which were not particularly related to the cardiovascular apparatus. Reaction to pain was tested on a modification of the Hardy-Wolff heat radiation apparatus. Levels of perception of pain were approximately equal. However, 39 patients reacted to pain with a lower stimulus -0.315 gram cl. per sec. per $\mathrm{cm}$. sq. as compared with 47 control subjects who reacted at $0.353 \mathrm{gram} \mathrm{cl}$. per sec. per $\mathrm{cm}$. sq. Ability to stand uncomfortable electric shock was lower in patients; 29 patients standing a mean of 2.5 units as against 50 control subjects standing a mean of 6 units. Units were arbitrary units of electrical current and are reported as re-

\footnotetext{
* The work described in this paper was done under a contract of the Office of Scientific Research and Development, Contract OEM cmr 157, with the Massachusetts General Hospital, Boston, Mass.
}

action level minus awareness level. In testing ability to maintain grip at 60 per cent of maximum using a Stoelting hand dynamometer 22 patients maintained a constant grip for 31 seconds. Fifty-six control subjects maintained a constant grip for $\mathbf{4 8}$ seconds. It was found that the patients did poorly on types of tests other than those which involve cardiovascular respiratory function.

It was concluded from this study that patients' disability was not limited to the cardiovascular-respiratory system alone.

Clinical, Chemical, and Physicochemical Studies on Human Plasma Preserved in the Liquid State at Room Temperature. By EUGENe L. LozNER and (by invitation) Lloyd R. Newhouser, Bethesda, Md.

The preservation of normal human plasma in the liquid state at room temperature for periods up to 2 years has been evaluated by an analysis of administrations and by chemical and physicochemical studies. Over 1300 transfusions of liquid plasma more than a year old have been performed with an untoward reaction rate actually less than that of fresh or dried plasma. The plasma had lost none of its therapeutic effectiveness as an antishock or anti-hypoproteinemia agent as judged by clinical response, increase in blood pressure, decrease in pulse, and increase in plasma proteins.

The amino acid nitrogen and polypeptide nitrogen content increased slightly during the second year of liquid storage. The actual values indicate hydrolysis to this degree of less than 2 per cent of the original protein. The electrophoretic pattern of liquid plasma 2 years old shows the mobilities of the globulin factors to be nearer and invading somewhat the albumin component. Stored plasma shows a slightly greater osmotic effectiveness than fresh plasma in vitro. Neither the chemical nor the physicochemical changes are of suffcient magnitude to preclude the use, for its colloid content, of properly prepared liquid plasma stored up to at least 2 years.

The Mechanism of Pain in Aviators" "Bends". By Joseph P. Webb, George L. Enget, John Romano, Henry W. Ryder, Charles D. Stevens (by invitation), M. A. Blankenhorn, and Eugene B. Ferris, JR., Cincinnati, Ohio.

Because of the effect of denitrogenation (preflight oxygen inhalation) in preventing decompression sickness, there has been general agreement that the symptoms are caused by the appearance of bubbles of gas, chiefly nitrogen, incident to decompression. Moreover, the view has been widely held that the pain of "bends" is based on tissue ischemia secondary to vascular occlusion by bubbles; however, the following evidence suggests that distortion of tissues by extravascular bubbles is the more likely explanation.

(1) Nitrogen clearance studies indicate that bubble formation would be expected to occur first in tissues having the poorest blood supply, and last in arterial blood. 
(2) It has not proved possible to demonstrate bubbles in venous blood during "bends".

(3) The application of external pressure to a painful area relieves the pain, despite the fact that the pressure may oblierate blood flow.

(4) The specific pain pattern may be reproduced exactly by re-exposure after intervals as long as 6 hours, indicating that the circulation has not removed the bubble.

(5) The vascular phenomena which sometimes complicate decompression sickness (skin and neurologic manifestations) have been demonstrated to be of spastic rather than of embolic nature.

(6) Finally, roentgenographic studies of the knee joint show a highly significant correlation between the presence of pain in the region of the joint and the presence of extra-articular tissue bubbles which have a non-vascular distribution.

\section{READ BY TITLE}

The Mechanism of Shock from Burns and Trauma Traced With Radiosodium.* By Charles L. Fox JR., and Albert S. Keston (introduced by A. R. Dochez), New York, N. Y.

Investigations by Rosenthal in mice and by Fox in man have demonstrated the therapeutic efficacy of isotonic solutions of sodium salts in shock and have shown the occurrence of a large sodium deficiency. To explore further the relative shifts of sodium and water in normal and traumatized tissues, radiosodium was used.

Shock from both burns and trauma was standardized in mice by Rosenthal's technics. Isotonic saline containing $\mathrm{Na}^{24}$ was given before injury so that body sodium was "tagged" and in other animals was administered therapeutically during shock. Determination of $\mathrm{Na}^{24}$ and water content was performed in normal and injured tissues and in control animals.

The results show that in traumatized tissues: (1) the water content increased up to 10 per cent, whereas the sodium content increased from 300 to 500 per cent; (2) the volume of extracellular fluid was greatly increased; often all the tissue water appeared to contain sodium, indicating entrance of sodium into cells normally devoid of it. The extracellular fluid of uninjured organs was reduced. The total volume of extracellular fluid was decreased more than 50 per cent; in severe human burns, similar reductions were found.

The data indicate a great "loss" of sodium into traumatized tissues, accompanied by a marked reduction in the total volume of extracellular fluid. The circulatory collapse characteristic of shock, and the usually concomitant decrease in plasma volume, are apparently the consequence of the sharp reduction in extracellular fluid volume. Accordingly, the primary therapeutic indication is rapid restoration to normal of the extracellular fluid volume, most efficiently accomplished by administration of solutions which have the effect of rapidly restoring

* Work done under a contract with the Office of Scientific Research and Development. to normal concentration the chief extracellular component, namely sodium.

The Effect of Vitamin $K_{1}$ Oxide upon the Anticoagulant Action of Dicoumarol. By Charles S. Davidson, JoHN H. Freed, and Harriet MacDonald (introduced by Clark W. Heath), Boston, Mass.

The usefulness of dicoumarol, in contrast to the rapid action of heparin, in patients in whom delayed coagulability of the blood is desired, is limited by the time required both for delayed blood coagulability to occur and for normal coagulability to return after discontinuing the administration of dicoumarol. Vitamin $\mathrm{K}$-like substances and vitamin $K_{1}$ oxide have been shown to have an action antagonistic to that of small amounts of dicoumarol on the blood prothrombin concentration. The present study concerns the effect of vitamin $\mathrm{K}_{1}$ oxide upon the action of dicoumarol given in doses sufficiently large and over a sufficiently long time not only to reduce the blood prothrombin concentration but also to prolong the blood coagulation time significantly.

Five patients in whom delayed blood coagulability was desired were given dicoumarol orally. The initial dose was 0.8 gram, followed by 0.2 gram daily. Administration was continued until the venous blood coagulation time, as measured by a modification of the method of Lee and White, was 15 minutes or longer. This required a total dose of from 1.0 to 2.0 grams given over 3 to 8 days. At this time, vitamin $K_{1}$ oxide was given as a single intravenous dose of 0.5 or $1.0 \mathrm{gram}$. The coagulation time then always returned to normal (6 to 12 minutes) in from $3 \frac{1}{2}$ to 10 hours. In 4 of the patients, this occurred in spite of the continued administration of the maintenance dose of dicoumarol. In 3 of the 4 , no increase in blood coagulation time again occurred in from 4 to 16 days. In the fourth patient; whose illness was complicated by obstructive jaundice, a prolonged coagulation time re-appeared 24 hours after the administration of the vitamin $\mathrm{K}_{1}$ oxide.

The administration of vitamin $\mathrm{K}_{1}$ oxide, as here reported, is, so far as is known, the first effective antagonism of the anticoagulant action of dicoumarol. The action of vitamin $K_{1}$ oxide is, however, slow compared to the rapidity with which the coagulation time of the blood returns to normal after cessation of the administration of heparin. Moreover, after an effective dose of vitamin $\mathrm{K}_{1}$ oxide, the administration of dicoumarol will not again prolong the coagulation time until from 4 to 16 days later. By contrast, resumption of intravenous heparin has a prompt action. Thus, dangers and inconveniences still attend the use of an anticoagulant as difficult to control as is dicoumarol.

The Absorption and Excretion of Penicillin Following Continuous Intravenous and Subcutaneous Administration. By Lowell A. Rantz and (by invitation) W. M. M. KIRBY, San Francisco, Calif.

The absorption and excretion of penicillin during continuous intravenous administration has been studied in a 
group of syphilitic individuals under basal conditions. The concentration of penicillin obtained in the plasma was proportional to the amount administered Twentyfive hundred units per hour induced a concentration of 0.05 unit per ml.; 5,000 units per hour, 0.10 unit per ml.; 10,000 units per hour, 0.2 unit per $\mathrm{ml}$; and 20,000 units per hour, 0.4 unit per $\mathrm{ml}$.

Seven hundred and fifty to $1,000 \mathrm{ml}$. of plasma per minute were cleared of penicillin by the kidney, a rate which indicates that the renal tubule is primarily involved in the excretion of this substance. Infusion of penicillin in quantities up to 20,000 units per hour failed to establish a maximum rate of tubular excretion ( $\mathrm{Tm}$ ). Excretion is quantitative and the rate is unaffected by the minute volume of urine.

The plasma concentrations of penicillin were determined during its routine administration to sick individuals and were found to approximate those obtained during controlled study if the intravenous route were utilitized. Subcutaneous infusion resulted in levels only 50 per cent as great.

\section{Effect of Sulfonamide Chemotherapy upon Experimental} Bacterial. Pneumonia in the Presence of Influenza Virus. By Carl G. Harford (by invitation), Mary Ruth Smith (by invitation), Charlotte McLeod (by invitation), and W. BARRY Wood, JR., St. Louis, Mo.

Most of the deaths occurring in the influenza pandemic of 1918 are thought to have been due to secondary bacterial pneumonia. Although it has been assumed by many that such bacterial infections can be controlled by sulfonamide chemotherapy, no proof has been offered that the sulfonamide drugs are effective in the presence of influenza virus.

This problem has been studied experimentally in mice infected with Type A influenza virus and either Type I pneumococci or hemolytic streptococci. Experiments have been carried out using both lethal and sublethal doses of virus together with doses of bacteria which produce fatal pneumonia in the absence of virus. The infection has been initiated by intrabronchial inoculation of virus and bacteria. If untreated, animals thus infected die within 48 hours of a fulminating bacterial infection. The treated animals survive the bacterial infection, and when a lethal dose of virus is employed, they die between the fifth and ninth days. If sacrificed on the fifth day, their lungs contain no bacteria.

It was also shown that a mild pulmonary infection can be produced in rats by intrabronchial inoculation of influenza virus. Pneumococcal pneumonia superimposed upon the virus lesion was found to respond to chemotherapy.

It is concluded from these studies that sulfonamide drugs are effective in the treatment of experimental bacterial pneumonia, even in the presence of a lethal dose of Type $A$ influenza virus.
The Effect of Testosterone and Thiouracil on the Metabolic Disturbances of Progeria. By N. B. TALBot, A. M. Butler, and E. A. Maclachlan (by invitation), Boston, Mass.

Prolonged metabolic studies on a 6-year-old, dwarfed, cachetic boy with typical progeria showed that:

1. The food he assimilated was adequate for rapid growth in a normal child, yet he had not grown for several years.

2. Weight gain, nitrogen deposition, and body growth were induced by testosterone therapy. This showed that the patient could grow.

3. However, it was then noted that: (a) testosterone gradually lost its effectiveness; $(b)$ he should have gained more weight (muscle) according to nitrogen, potassium, sodium, chloride, calcium, and phosphorous balance measurements than he actually did; and, $(c)$ he had a very high energy output. This suggested that he might be gaining muscle at the expense of body fat or carbohydrate required for energy production.

4. To reduce the energy metabolism governed by the thyroid, thiouracil was given in addition to testosterone. This resulted in a reduction in energy output (BMR, insensible weight loss) and a simultaneous and striking gain in weight with a corresponding nitrogen storage. During this course of therapy, the patient changed from a thin, hyperactive individual to a taller and more plump and normally placid person.

It is concluded that progeria is associated with marked metabolic disturbances, which can be modified by a specific therapy.

A Study of Proteolytic Enzymes in Lymph.* By PAUL C. Zamecnik and John B. Graham (introduced by Oliver Cope), Boston, Mass.

Recent studies on experimental burns have called attention to the zone of partially damaged cells which surrounds the severely burned area as a possible site of origin of toxins. In the present investigation, a search for proteolytic enzymes was made in lymph from dogs' legs, before and after burning the legs by immersion into water at $90^{\circ} \mathrm{C}$. for 15 seconds.

With the aid of peptide substrates, the presence of an aminopeptidase was detected, hitherto undescribed in lymph. In the lymph draining the burned area, the activity of this enzyme rose from 6 - to 20 -fold within an hour after the burn, and'continued to remain elevated for a period of hours thereafter. The known characteristics of this enzyme are as follows: it has a $\mathrm{pH}$ optimum around 7.5 , hydrolyzes 1-leucylglycylglycine preferentially, and does not require the presence of any known activator.

Following a crushing injury to the dog leg, this enzymatic activity was found at increased levels in the efferent

\footnotetext{
* The work described here was done under a contract, recommended by the Committee on Medical Research, between the Office of Scientific Research and Development and the Massachusetts General Hospital.
} 
lymph from this area. An enzyme with properties so far identical to those described has been found in saline extracts of normal dog muscle. The same type of enzymatic activity was found in bleb fluid obtained from human burns.

A Limited Study of the Recent Influenza Epidemic. By Maxwell Finland and (by invitation) Mildred W. Barnes and Bernardo A. Samper, Boston, Mass.

Isolation of virus from acute cases of influenza was accomplished by inoculation of pharyngeal washings intranasally in mice and into the allantoic sac of the developing chick embryo. Evidence of the successful isolation was obtained in the first egg passage and in the third to the sixth mouse passages. All the viruses isolated from patients during the month of December and the early part of January were identified as influenza A. High titers of complement-fixing antibodies for the laboratory-adapted PR-8 strain of influenza A developed during convalescence in all of the patients from whose pharyngeal washings the virus was isolated. A rise in antibodies was also demonstrated in similar cases of clinical influenza from which isolation of virus was not attempted. In addition, a similar virus was obtained during the height of the epidemic, from the lung of an acutely fatal case of pneumonia which followed influenza.

After the end of January, cases of clinical influenza were again observed and virus was readily isolated from pharyngeal washings of acute cases and from the lungs of fatal cases. Evidence has been obtained which suggests that this may be a different virus or a variant.

Serological studies were made in a number of severe cases of bacterial pneumonia, observed shortly after the height of the epidemic. Many of these patients responded poorly to the usual treatment. In the serum of most of these patients, significant and sometimes high titers of antibodies for influenza A were demonstrated.

Some Effects of the Administration of Amino Acids in a Patient with Idiopathic Steatorrhea.* By KENDALL Emerson, Jr. and William W. Beckman (introduced by T. M. Rivers), New York, N. Y.

Amino acids in the form of an enzymatic hydrolysate of casein were administered to a 27-year-old woman with idiopathic steatorrhea, hypoproteinemia, and hypocalcemia. After a control period on a measured diet, 40 grams of the daily dietary protein were replaced by an equal amount of the casein hydrolysate as a 10 per cent solution given intravenously in 3 daily portions for one week. During the control period, the patient was in negative nitrogen and phosphorus balance. Two days after the commencement of intravenous amino acids, the diarrhea ceased and the stools became normal. During the week of treatment, there was a marked retention of nitrogen, averag-

* The Bureau of Medicine and Surgery of the U. S. Navy does not necessarily undertake to endorse views and opinions expressed in this abstract. ing 3 grams daily; both fecal and urinary nitrogen decreased. No change in calcium or phosphorus excretion occurred. Following cessation of therapy, the diarrhea returned within 4 days. The patient was then given 45 grams of the amino acid mixture by mouth daily for one week, in addition to the control diet. Again the stools promptly returned to normal, and a marked nitrogen retention occurred. This time there was a definite increase in the retention of calcium and phosphorus.

Thiamine Metabolism and Excretion in Man. By Benjamin Alexander, Greta Landwehr, and Frances Mrtchell (introduced by Mark D. Altschule), Boston, Mass.

The exact relationship between the amount of administered thiamine and its urinary excretion requires elucidation. Furthermore, a large proportion of administered thiamine cannot be recovered in the excreta.

In 3 normal subjects, intramuscularly injected thiamine was increased daily by both geometric and arithmetic proportion. Experiments by different quantitative technics gave the same excretion curve. Thiamine determinations were made by the specific colorimetric method developed here. In one subject, analyses of urinary pyrimidine were also made.

Urinary thiamine was closely related to administered thiamine, rose with increasing daily doses, was 50 per cent at the $10 \mathrm{mgm}$. dose, and 80 to 90 per cent at the $35 \mathrm{mgm}$. dose.

All excretion curves differed only slightly. Other isolated observations here and in the literature were in good accord.

One subject received 1.086 grams of thiamine in 51 days; 82 per cent was recovered as urinary thiamine and 16 per cent as pyrimidine; $0.5 \mathrm{mgm}$. per day was unaccounted for. A 9-day balance study, beginning long after discontinuation of parenteral injection, gave the same value. Since fecal thiamine is of this magnitude and since some thiamine appears in sweat, probably all the thiamine taken is excreted as thiamine or pyrimidine.

The amount of thiamine which can be converted into pyrimidine was measured during the period of high thiamine dosage. The subjects differed in age, weight, metabolism, and surface area, and represented both sexes. Maximal pyrimidine conversion was proportional to the oxygen consumption per unit of surface area.

\section{Diffusion of Water Through Living and Dead Human Skin with the Identification of the Diffusion Inhibiting Layer.* By George E. Burce and (by invitation) Travis Winsor, New Orleans, La.}

The rate of water loss from the surface of the skin of living and dead human subjects was measured quantitatively. It was found that the rate of water loss through dead skin studied within 2 hours of death, 4 weeks after death, or after repeated freezing and thawing was essen-

* Aided by a grant from the Rockefeller Foundation. 
tially the same and of the same order as the loss through intact skin of living subjects resting quietly in a comfortable environment (temperature $75^{\circ} \pm 1^{\circ} \mathrm{F}$.; relative humidity 50 per cent \pm 2 per cent). After an interval as long as 60 minutes, no water accumulated in the collecting chambers sealed to the intact living skin of the comfortable resting subject, indicating the absence of sweat gland activity. The rate of water loss through the skin of 2 patients with atrophy of sweat glands who were unable to sweat and who suffered from summer heat was the same as that through dead skin or the intact skin of resting comfortable subjects. It was concluded that water lost through the skin of normal subjects resting quietly in a comfortable environment is lost by diffusion and not through sweating by the sweat glands. The rate of diffusion was found to vary directly with the temperature of the skin. The rate of diffusion of water through human skin was essentially the same as through the "skins" of fruits and vegetables.

By isolating the layers of the intact and dead human skin by means of cantharides plasters, mechanical methods, and fat solvents to remove the superficial fats and oils, and checking the completeness of removal by tissue sections, the rate of diffusion through the various layers of the skin was determined. It was found that the thin dead superficial layer, the corneum, was the main layer responsible for the inhibition of diffusion through human skin.

Factors Which Influence the Number of Hemolytic Streptococci in the Air of Hospital Wards. * By Morton Hamburger, Jr. (introduced by Dr. C. Philip Miller), Camp Carson, Colo.

Studies of the distribution of hemolytic streptococci in the environment of patients harboring these microorganisms in the nose and throat show that they accumulate rapidly in bedclothing and floor dust. Cultures of bedlinen made as soon as 4 hours after admission of a patient sometimes revealed thousands of hemolytic streptococci. Samples of dust frequently showed tens of thousands around a single bed. Air cultures on a "streptococcus sore throat" ward for 4 consecutive periods-quiet, during sweeping, quiet, during bedmaking-showed striking increases in hemolytic streptococci during sweeping and bedmaking. Daily air cultures in several locations in the ward showed that fluctuations in the number of hemolytic streptococci in the air closely approximated those of the total saprophytic (i.e., floor and bedclothing) bacteria.

Streptococci expelled by the patient or carrier usually fall rapidly to the floor or bedclothing, which become important secondary reservoirs of these microorganisms. Cultures of saliva of persons with "positive" throat

* From the Commission on Air-Borne Infections, Board for the Investigation and Control of Influenza and Other Epidemic Diseases in the United States Army, Preventive Medicine Service, Office of the Surgeon General, U. S. Army. cultures often show hundreds to millions of hemolytic streptococci per milliliter, especially in the acute stages of infection. Nasal cultures frequently show large numbers. Moreover, the actual number of hemolytic streptococci recovered from bedclothing of patients with "positive" nose cultures was approximately one hundred times as great as from those in whom only the throat or saliva were positive.

The numbers of hospital cross infections caused by different types of hemolytic streptococci paralleled the numbers of each type recovered from the air.

Hyaluronidase Concentration and Spermatozoa Concentration in Semen as a Gauge in Fertility. By Nicholas T. Werthessen, Saul Berman, and Boris E. GreenBERG (introduced by J. E. F. Riseman), Boston, Mass.

The demonstration of the presence of hyaluronidase in the seminal fluid and its probable function in fertilization (dissolution of the egg's corona) has provided another factor with which to estimate the fertilizing capacity of a particular semen specimen.

A technic, based on the reduction of viscosity of hyaluronic acid by hyaluronidase, has been developed. Accuracy of the method was considered as \pm 7 per cent when the enzyme concentration was expressed as an arbitrary unit with $0.1 \mathrm{ml}$. of semen as the reference volume.

The concentration of the enzyme has been found to be related to the sperm concentration in linear fashion. The equation $\mathrm{M}=0.493+0.858 \mathrm{H}$ where $\mathrm{M}=$ Millions of sperm per $\mathrm{ml}$. and $\mathrm{H}$ the concentration of enzyme (both as logarithmic units) was found to be the best expression of the relationship.

Since it was found that, even with elaborate precautions in counting, the error of a semen count for a single specimen had to be considered as 20 per cent, it is suggested that the use of the hyaluronidase index would provide a better gauge of therapies designed to raise the rate of spermatozoa production than counts of the sperm population.

Work Capacity and Blood Sugar in Adrenocortical Deficiency: Effect of Pork Adrenal Cortex Extract. By Cyril M. MacBryde and (by invitation) F. A. de la Balze, St. Louis, Mo.

Studies were done upon 6 patients with Addison's disease who had severe hypoglycemia and muscular weakness despite adequate control of salt metabolism and blood pressure with desoxycorticosterone or beef adrenal cortex extract. Pork cortical extract, when compared in parallel experiments with beef cortical extract, gave the following results:

(1) Better absorption of ingested glucose.

(2) Prevention of the hypoglycemic phase at the second or third hour in oral or intravenous glucose tolerance tests.

(3) Prevention of blood sugar fall during prolonged fasting. 
(4) Intramuscular injection of pork extract produced a fall in the venous blood sugar, reaching a maximum in 2 or 3 hours. This was puzzling until we found that it was accompanied by a rise in the capillary (arterial) blood sugar. No such changes occurred with comparable doses of beef extract. The greater arterio-venous difference in the blood sugar following pork extract apparently reflects an increased utilization of glucose by the muscles.

An increase in glucose metabolized by the muscles should result in greater work capacity. Two types of work experiments were performed to test this hypothesis : finger ergometer, and stair-climbing. Performance was improved in all trials with pork extract, the increase averaging 40 per cent. With beef extract, there was no significant improvement. The extreme fatigue following work in the control tests and after beef extract was not present after pork extract.

Capillary and venous blood sugar determinations before and during the work experiments indicate that the pork extract caused release of liver glycogen and promoted muscle utilization of glucose. The greater effect of the pork extract is apparently due to its higher content of steroids with $\mathrm{O}$ or $\mathrm{OH}$ on $\mathrm{C}_{11}$.

The Hemodynamics of Neurogenic Hypertension. By Richard J. Bing (introduced by E. Cowles Andrus), Baltimore, Md.

The hemodynamics of neurogenic hypertension was investigated in a series of 6 unanesthetized dogs. Cardiac output was measured after the method of Fick by inserting a catheter into the right ventricle; mean blood pressure was determined with the Hamilton manometer. P-aminohippuric acid and creatine clearances were used to obtain renal plasma flows and filtration rates respectively. Changes in the blood flow through the fore-limb were followed with the plethysmograph. The total peripheral resistance, renal resistance, and limb resistance were derived with the formula of Aperia.

After having established control values, the animals were made hypertensive by the Heymans operation. Changes in the cardiac output, renal plasma flow and filtration rate, and in the blood flow through the limb were followed at regular intervals.

The most striking change accompanying the development of neurogenic hypertension was an increase in the heart rate and the cardiac output, the systolic discharge remaining constant. The renal blood flow and filtration rate showed no significant change, while the flow through the limb rose in every instance. The total peripheral resistance rose slightly in 2 animals and remained constant in the rest. The renal resistance, on the other hand, increased more than 50 per cent while the vascular resistance in the forelimb fell.

These results indicate that the development of neurogenic hypertension is accompanied by a rise in cardiac output, constriction of the renal afferent arterioles, and accelerated circulation in the extremities. They are indicative of increased sympathetic tone.
Laryngeal Epilepsy Due to Increased Intrathoracic Pressure.* By ROBERT W. Wilkins and (by invitation) Carl K. Friedland, Boston, Mass.

Certain patients with pulmonary disease after severe paroxysms of coughing or laughing may temporarily lose vision and even consciousness. Some normal subjects studied during the Valsalva experiment (inhaling deeply and then forcibly expiring against a closed glottis) also temporarily lost vision. In such subjects, arterial pressure (measured by the Hamilton method) varied as follows: with the onset of the strain it rose sharply (presumably due to the increased intrathoracic pressure). After 2 or 3 seconds, arterial and especially pulse pressure began to fall; and with the "blackout" reached low levels. In others, while the strain was still held, there was a recovery of the arterial pressure toward higher levels. On releasing the strain, there was a brief sharp drop in arterial pressure (presumably due to the removal of intrathoracic support) followed by rapid rise to hypertensive levels. The pulse rate usually varied inversely as the arterial pressure. In certain subjects who "blacked out," the cardiac output judged by ballistocardiograms and roentgenograms decreased markedly during the test.

Two patients with pulmonary disease who complained of "blackout" after coughing showed similar results during the Valsalva test. In one of them, the effect could be simulated by voluntary coughing. These results indicate that this form of "laryngeal epilepsy" is due to preventing venous return to the heart by increasing intrathoracic pressure, with the result that cardiac ouput is so reduced that an adequate arterial pressure cannot be sustained.

The Effect of Increased Intra-Abdominal Pressure Upon Renal Function in Normal Human Subjects.* By Stanley E. Bradley and Geraldine P. Bradley (introduced by C. S. Keefer), Boston, Mass.

Renal function was studied by clearance and saturation methods (Smith) before, during, and following the sudden elevation of intra-abdominal pressure produced by inflating a snugly fitting pneumatic corset to $80 \mathrm{~mm}$. Hg. Intra-abdominal pressure measured under similar conditions by means of duodenal or rectal balloons and by direct catheterization of the inferior vena cava or renal vein revealed increments of 15 to $30 \mathrm{~mm}$. $\mathrm{Hg}$ when the abdominal wall was as relaxed as possible. Voluntary bearing-down resulted in a further increase in the pressure, as high as $110 \mathrm{~mm} . \mathrm{Hg}$ in a muscular individual.

Following the rise in intra-abdominal pressure, the urine flow decreased sharply, the concentration of the urinary solutes (inulin, mannitol, diodrast, and sodium p-amino hippurate) increased, and a moderate proteinuria was noted on several occasions. The rate of urine flow

* This work was done under a contract, recommended by the Committee on Medical Research, between the Office of Scientific Research and Development and the Massachusetts Memorial Hospitals. 
tended to return slowly to the control level during prolonged application of the pressure belt.

The glomerular filtration rate and the effective renal plasma flow fell immediately, at the same time and to the same extent, so that the fraction of plasma filtered at the glomerulus remained unchanged through the period of increased pressure. Here, again, restitutive processes were apparent in the gradual return of the filtration rate and effective renal plasma flow toward the base-line. Following release of the pressure, all values returned to the control levels. Reactive hyperemia was not observed.

It was also found that the maximal rates of tubular reabsorption of glucose and excretion of diodrast were reduced during the period of elevated intra-abdominal pressure to the same extent as the plasma flow, so that the ratio between renal blood flow and the mass of functioning tubular tissue as measured by glucose and diodrast $\mathrm{Tm}$ remained unaltered. This change in maximal tubular activity rates could not be ascribed to loading reduction secondary to the fall in blood flow and filtration rate since the calculated load/ $\mathrm{Tm}$ ratio was maintained above 1.2 in all instances. Again, a gradual shift toward the base-line level was observed during long periods of increased pressure and a rapid return to control values followed release of the pressure.

Thus, it appears that increasing the intra-abdominal pressure results in the total cessation of urine formation in a large segment of renal tissue.

The Capillary Circulation of the Normal Dog.* By John G. Gibson, 2ND, and (by invitation) ARNold $M$. Seligman, and Wendell C. Peacock, Boston, Mass.

The capillary content of plasma was determined by means of radioactive-iodo-protein, and of red cells, by radioactive iron and hemoglobin measurements on 5 normal dogs under morphine narcosis. Plasma volume was measured by the dye method and red cell volume by radioactive iron.

Only one-fifth of the total blood is in circulation through the capillary bed at one time and not over 5 per cent of total blood is in the capillaries of any organ. The relative ratio of capillary blood content of whole organs is liver and muscle, 6; spleen and gut, 3; lung, kidney, and skin, 2; and, heart and brain, 1.

The hematocrit of capillary blood in the spleen is always greater and that of all other organs is less than the hematocrit of arterial blood. Values for liver, lung, muscle, and skin range from 32 to 38 ; for kidney, heart, and brain, from 20 to 29; and for bowel, 12. The average arterial hematocrit was 45 and the average body hematocrit was 40.

All the red cells in the capillary bed are in motion at all times in the resting state. No evidence for the existence of any considerable "blood depots" (excluding mesentery and bone marrow which were not measured) was found.

* Work done under contract with the Office of Scientific Research and Development.
The Treatment of Hyperthyroidism with Thiouracil. By Louis J. Soffer and (by invitation) MORLEY KERT and Lester Gabrilove, New York, N. Y.

Twenty-five patients with well-defined Graves' disease were treated with thiouracil for a period varying from 6 weeks to 6 months. For the first 4 weeks, the dosage was 1 gram daily, divided into 5 doses, and 2/10 gram daily thereafter. Weight, pulse, blood pressure, basal metabolic rate, circulation time, electrocardiographic tracing, magnesium partition, complete blood counts, liver function studies, and renal function studies were recorded before and during the course of thiouracil therapy. The patients were carefully observed for evidence of sensitivity to the drug.

Five patients showed signs of drug toxicity, 2 developed a mild leukopenia, 1 a rash and fever, 1 edema, and 1 conjunctivitis. Approximately $2 / 3$ responded well to thiouracil therapy, with lowered basal metabolism and pulse rates, an increase in weight, and subsidence of the symptoms of hyperthyroidism, although the tremor and eye signs showed no decrease. Nine subsequently came to operation (thyroidectomy). As far as could be determined microscopically, the extirpated glands in the patients who received combined thiouracil and Lugol therapy appeared identical with those of patients who received Lugol's solution alone. There was no evidence of increased hepatic, renal, or cardiac injury as a result of the treatment.

Thiouracil in the Treatment of Thyrotoxicosis. By Robert H. Williams and (by invitation) Howard M. Clute, Boston, Mass.

One hundred and five patients with thyrotoxicosis have been treated with thiouracil for from 5 days to 1 year. One third have been treated for more than 6 months. Within 4 to 5 weeks, there was a clinical remission of the disease with a drop in the basal metabolic rate to normal. Patients who were given iodine before thiouracil treatment responded more slowly. Sometimes thiouracil caused a transitory exacerbation of exophthalmos in patients with malignant exophthalmos. Usually the size of the thyroid gland became definitely smaller after ove or more months of thiouracil. In a few cases, estimations of the protein bound iodine of the plasma revealed a normal concentration after a few weeks of treatment. The plasma iodine became normal before the metabolic rate did.

The complications of thiouracil therapy have consisted of agranulocytosis (1 case), morbilliform rash, urticaria, fever, arthritis, swelling of the legs, and enlargement of the submaxillary salivary glands. These complications have been quite rare with reduction in dosage of thiouracil.

Although a satisfactory response in the thyrotoxic state occurred, 30 patients were subjected to thyroidectomy. The operative and post-operative course was relatively smooth, particularly in the patients treated with thiouracil for 3 weeks or longer preceding the operation. A chemical analysis of the thyroid glands 
removed showed a great variation in the concentration of thiouracil, but there was no correlation with the therapeutic response. The content of thyroxin iodine in the gland was extremely low, being almost absent in a few cases. Histological changes were quite unlike those of iodized thyroid glands. There was marked cellular hyperplasia, disappearance of colloid, increased interstitial tissue, and scattered infiltration with lymphocytic germinal centers.

The most desirable dosage of thouracil has not yet been established. However, we have found that this drug is very rapidly absorbed from the gastro-intestinal tract and is disseminated throughout all of the tissues and fluids of the body. More than one-half of the ingested drug is broken down in either the gastro-intestinal tract or the tissues of the body, the remainder being excreted at a fairly rapid rate in the urine. Patients can be satisfactorily treated with thiouracil without performing estimations of its concentration in the blood.

The Effect of Thiouracil on Hyperthyroidism and on the Uptake of Radioactive Iodine in Patients with Adenocarcinoma of the Thyroid and Functioning Metastases.* By Louis Leiter and (by invitation) S. M. SeIdlin, L. D. Marinelit, and E. J. Baumann, New York, N. Y.

The action of thiouracil was studied in 2 patients with adenocarcinoma of the thyroid, extensive pulmonary and osseous metastases, and moderate to severe hyperthyroidism. In one case, there was no significant thyroid tissue in the neck; in the other, the non-cancerous right lobe was excluded as a possible source of hyperthyroidism. The former responded to large doses of iodine with a partial remission of the signs of hyperthyroidism; the latter was, if anything, rendered more hyperthyroid by iodinization.

Thiouracil produced a typical remission in both patients, as evidenced by a striking fall in basal metabolism, gain in weight, increase in serum cholesterol, and decrease in organic blood iodine. No untoward reactions were observed. The beneficial effect lasted only during the period of administration of the drug.

The uptake of radioactive iodine by the metastatic thyroid nodules was used as a criterion of functional activity. The effect of thiouracil on this process will be described.

Observations on the Administration of $V$ itamin $P$ in Cases of Rheumatic Fever. By J. F. RINEHART and (by invitation) Henen Johnson, San Francisco, Calif.

Eleven children with active acute rheumatic fever have been treated with crude hesperidin or related flavone containing substances. Seven children received crude hesperidin orally in doses of 0.75 to 1.5 grams daily and 4 received other substances of supposed vitamin $\mathbf{P}$ activity.

* Aided by a grant from the Dazian Foundation for Medical Research.
Four of the cases had shown persistent activity of the rheumatic process for periods of 2 to 4 months at the time the treatment was instituted. All cases exhibited improvement with progressive slowing of the sedimentation rate following the therapy. Significant slowing of the sedimentation rate occurred in most instances within 2 weeks. Graphic representation of the sedimentation rates strongly suggests that improvement was related to this therapy, although it is evident that a larger series of cases must be studied. Observations on capillary permeability are briefly reported.

The use of vitamin $P$ in rheumatic fever is not without a rational basis. Experimental studies have suggested that vitamin $C$ deficiency may be a factor in the pathogenesis of rheumatic fever. Vitamin $P$ was postulated by Szent-Györgyi as a substance which acted in conjunction with vitamin $C$ in maintaining a normal state of permeability in the capillary wall. While dietary experiments in animals have not shown conclusively that vitamin $\mathbf{P}$ is an essential food factor, a number of clinical observations have supported its physiological activity in certain types of purpura. Purpuric manifestations are not uncommon in rheumatic fever. In view of the data suggesting the operation of an allergic influence in rheumatic fever, it is noteworthy that the reputed therapeutic value of vitamin $P$ has been in cases of "vascular" purpura including types which are believed to be allergic.

Etiological and Clinical Studies on Endemic Exudative Tonsillitis and Pharyngitis. By Commission on Acute Respiratory Diseases, Station Hospital, Section 2. (Board for the Investigation and Control of Influenza and Other Epidemic Diseases in the Army, Preventive Medicine Service, Office of the Surgeon-Geheral, U. S. Army). Presented by Elias Strauss (introduced by Charles H. Rammelkamp), Fort Bragg, N. C.

The B-hemolytic streptococcus is generally considered to be the commonest cause of exudative tonsillitis and pharyngitis. In such cases, the presence of the organism is thought to be associated with a characteristic clinical pattern. The present study casts doubt on the validity of these concepts. A group of 116 men admitted to a military hospital because of exudative pharyngitis or tonsillitis were studied. Only 56 of the patients (48 per cent) had B-hemolytic streptococci in one or more throat cultures. Furthermore, only 28 of the 56 developed a significant increase in streptococcal antibodies (antistreptolysins) during convalescence. These 28 patients, constituting 25 per cent of the whole, also differed from the rest in the numbers of streptococci present in cultures, in the amount of exudate in the throat, in the height of the leukocyte response, and in the clinical pattern of the illness. In contrast, patients with streptococci but without an antibody response resembled cases of exudative pharyngitis without streptococci. Both of the latter groups bore a clinical resemblance to cases of undifferentiated respiratory disease. 
Twelve per cent of all patients had roentgen and laboratory evidence of primary atypical pneumonia. These cases were distributed throughout the whole group. Exudative pharyngitis, whether due to B-hemolytic streptococcus or not, may be associated with or superimposed on other forms of respiratory disease.

Reversible Inactivation of the Substance Inducing Transformation of Pneumococcal Types.* By MACLYN McCarty (introduced by O. T. Avery), New York, N. Y.

Recent studies on the chemical nature of the substance inducing transformation of pneumococcal types have provided strong evidence that this substance is a nucleic acid of the desoxyribose type. Purified preparations of desoxyribonucleic acid isolated from Type III pneomococci are capable in minute amounts of causing unencapsulated variants of Pneumococcus Type II to acquire the capsular structure and type specificity of Pneumococcus Type III. These facts suggest that nucleic acids in general may possess biological specificity. In an attempt to obtain information concerning the chemical basis of this specificity, the reversible inactivation of the transforming substance has been studied.

Ascorbic acid causes rapid and complete inactivation of the transforming substance. Among other compounds tested, only those having the di-enol configuration of ascorbic acid have proved effective in inactivation, and in each case traces of copper catalyze the reaction.

In the presence of glutathione and certain other sulfhydryl compounds, ascorbic acid inactivation is prevented. Moreover, transforming material which has been completely inactivated by ascorbic acid can be quantitatively reactivated by treatment with glutathione. Thus, the specific substance presumably possesses chemical groups which are susceptible to reversible oxidation and reduction and which are present in the reduced state in the biologically active molecule.

Filtering Action of the Guinea Pig Spleen for FoaKurloff Cells. By RoBert W. HEINLE and (by invitation) David K. Heydinger, Cleveland, Ohio.

Increase of Foa-Kurloff cells in the blood of guinea pigs after estrogen administration and during pregnancy is a recognized phenomenon. Normal and splenectomized guinea pigs were given diethylstilbestrol in daily subcutaneous doses of 0.01 and $0.05 \mathrm{mgm}$. Spleens of such animals contained large numbers of Foa-Kurloff cells. Both groups of animals showed a peak of Foa-Kurloff cells in the blood with return to normal numbers in spite of continuous injection. Splenectomized animals reached the peak sooner, the peak was higher, and the duration of the response was longer than in guinea pigs with spleens.

The Foa-Kurloff cell has been described variously as

* The Bureau of Medicine and Surgery of the U. S. Navy does not necessarily undertake to endorse views and opinions expressed in this abstract. a monocyte or lymphocyte. Results of this experiment indicate it is neither but is probably a reticulo-endothelial cell produced by the stimulus of estrogen. The spleen apparently removes considerable numbers of these cells from the blood stream. Lymph nodes and other reticulo-endothelial organs did not exhibit this filtering mechanism, even in splenectomized animals.

\section{Orthostatic Hypotension in Normal Young Men Following Physical Exertion, Environmental Thermal Loads, or Both. By Ludwig W. Eichna and William Bennett Bean, Fort Knox, Ky.}

Symptomatic, and usually disabling, orthostatic hypotension was a common occurrence in healthy young men subjected to strenuous physical exertion or hot environments or both. The exertions ranged from severe, quickly exhausting effort to prolonged endurance hikes. The climatic stresses consisted of hot, dry $\left(120^{\circ} \mathrm{F}\right.$., relative humidity 15 to 20 per cent) and hot, humid $\left(90^{\circ} \mathrm{F}\right.$., relative humidity 95 per cent) environments.

The syndrome occurred with equal frequency in fit and unfit men and its manifestations were similar, regardless of the inducing stress. Bradycardia occurred often and in 2 men progressed to asystole which in one man persisted for 19 seconds. The duration of the hypotension varied from: $(a)$ a fraction of an hour to several hours after short severe exertion, (b) several hours to half a day after moderate prolonged exertion, (c) one to several days during rest and work in hot environments. The hypotension induced by a specific stress disappeared with repetition to the stress when it was exertion or with a continuation of it when thermal (acclimatization). It reappeared when the stress (especially thermal) was repeated after a long lapse. While erect, the symptoms and circulatory manifestations were prevented or, when present, alleviated rapidly by (a) moving the legs, (b) occluding the arterial circulation to the legs, and (c) removal to a cool room when the stress was thermal. Orthostatic hypotension is a common occurrence in normal men subjected to various stresses and represents one of the manifestations of the failure of the circulation to cope with the load imposed.

Hemolytic Reaction Due to $R$ h Incompatibility Following First Transfusion in a Woman Eight Years After Birth of an Erythroblastotic Child. By LAwRENCE E. Young, and Donald H. Kariner (introduced by John S. Lawrence), Rochester, N. Y.

It is now accepted that many transfusion reactions occurring during pregnancy or the post-partum period are due to the development of $\mathrm{Rh}$ antibodies in $\mathrm{Rh}$ negative women who are carrying or have recently given birth to $\mathrm{Rh}$ positive children. However, the danger of transfusing such women with $\mathrm{Rh}$ positive blood many years later is not fully realized. A recent case studied in the Strong Memorial Hospital emphasizes this hazard.

A radical mastectomy was performed November 15 , 1943, on a 40-year-old woman, blood group A1M Rh 
negative, who had given birth to an $\mathrm{Rh}$ positive erythroblastotic child February 7, 1936. No anti-Rh agglutinins could be demonstrated prior to operation. Postoperatively she received $500 \mathrm{ml}$. of blood from a donor whose group was A1MN Rh positive. This was followed by a mild chill, oliguria for 3 days, marked azotemia, and complete destruction of the donor's cells within 11 days as demonstrated by $\mathrm{MN}$ tests. Her anti$\mathrm{Rh}$ agglutinin titer rose to $1: 32,000$ on the 24 th day after transfusion.

It is recommended that $\mathrm{Rh}$ negative women receive only $\mathrm{Rh}$ negative blood, regardless of matching tests and regardless of the interval since possible sensitization to the $\mathrm{Rh}$ factor.

The Reaction in Humans to Phosphatide Fraction of Human Tubercle Bacilli. By Grorge T. HARrell, Winston-Salem, N. C.

The tubercle bacillus is one of the rare micro organisms which produce a similar reaction in the body if injected dead or alive. This is due in a large measure to the high content of lipids which are a distinguishing feature of the organism. The lipids have been little investigated biologically. R. J. Anderson, Yale University, has chemically analyzed the lipid fractions of tubercle bacilli. Florence Sabin has tested the biologic reactivity in guinea pigs and rabbits. In the study of human cases of sarcoid, the resemblance of the lesions in pathologic sections to photomicrographs accompanying Sabin's paper was striking. Lipid fractions were obtained from Anderson, the same materials used by Sabin, and injected intradermally in humans with tuberculosis, sarcoid, and normals. In tuberculars, the reaction to phosphatide was marked, with the production of giant chronic wheals which appeared on the second day and persisted for as long as 5 days. Patients with sarcoid and normal individuals did not exhibit this response. Wheals are usually acute reactions persisting only minutes, and may be produced by protein or carbohydrate materials. Since the phosphatide is a complex lipid containing a carbohydrate radical, it might be possible that the chronic wheal is produced by gradual breakdown in the tissues of the phosphatide and liberation of a carbohydrate fraction. This could act as a haptene. Microscopically, the reaction is characterized by an acute reaction with polymorphonuclear neutrophiles and eosinophiles, epitheloid cells, but no tubercles. In certain individuals, a late reactivation occurred in the second week at the sight of injection. This may represent the development of sensitivity to phosphatide or some breakdown product.

The Treatment of Syphilis in Six to Twelve Weeks by Triweekly Injections of Mapharsen: An Evaluation of the First 4800 Cases. By HarRy EAgLE, Baltimore, Md.

Early syphilis can be treated effectively and with reasonable safety by the administration of mapharsen at a unit dosage of approximately $1 \mathrm{mgm}$. per $\mathrm{kgm}$., repeated 3 times weekly for a total of 8 to 12 weeks. The end results on this schedule were comparable with those obtained with routine 18 months' treatment, and considerably better than those obtained in average clinic practice. The concurrent administration of bismuth subsalicylate, given intramuscularly once weekly at a dosage of 0.2 gram, had a markedly favorable effect on the final outcome, the estimated "cure" rate in such cases being approximately 90 per cent. Although the best results were obtained in patients receiving a total mapharsen dosage of 27 to $35 \mathrm{mgm}$. per $\mathrm{kgm}$. supplemented by weekly injections of bismuth, there was but little difference between patients on that dosage and those receiving 21 to $27 \mathrm{mgm}$. per $\mathrm{kgm}$. mapharsen. Reduction in the total amount of mapharsen below that level caused a significant increase in the proportion of treatment failures.

The results were somewhat better in primary than in secondary syphilis, with no significant difference between seronegative and seropositive primary syphilis. Race, sex, or age had no demonstrable effect on the outcome of treatment.

The Diagnosis of Raynaud's Disease in Men. By E. A. Hines, Jr., and (by invitation) N. A. Christensen, Rochester, Minn.

It has been assumed that Raynaud's disease occurs rarely in men, for it is usually estimated that from 90 to 97 per cent of the cases are among women. When Raynaud's phenomenon occurs in men, it is almost always considered secondary to some disease, such as thromboangiitis obliterans, which, if it cannot be immediately diagnosed, almost always will become evident when enough time has elapsed. As far as we know, a study of the adequacy of the diagnosis of Raynaud's disease has not been made in a large group of men and the verification of the diagnosis by an adequate follow-up study has not been carried out.

From 1920 to 1942 inclusive, the diagnosis of Raynaud's disease or questionable Raynaud's disease was made in 830 cases at the Mayo Clinic; 649 patients ( 78 per cent of the total group) were women and 181 (22 per cent) were men. The purpose of our study has been to try to evaluate the correctness of the diagnosis in the group of 181 men and to verify or disprove the diagnosis by a follow-up study carried out 2 or more years (average 8 years) after the onset of the Raynaud's phenomenon.

The criterion for the diagnosis of Raynaud's disease which we used in our study was similar to that suggested by Raynaud and by Hutchinson and was that outlined by Allen and Brown in 1930.

In 111 of the 181 instances of the disease in men, the diagnosis made at the time of the patient's original visit was Raynaud's disease and in 70 cases it was questionable Raynaud's disease. From our analysis of the data, we considered that the diagnosis of Raynaud's disease was adequate in 58 of the 181 cases, that it should have been questionable Raynaud's disease in 93 for such reasons as short duration of symptoms, unilaterality of Raynaud's phenomenon, unrecorded or questionable presence of 
arterial pulsation, and the possibility of primary diseases which might be causal and that it was almost certainly incorrect in 30 cases. Thus, in our opinion, 30 patients (17 per cent) received an incorrect diagnosis of Raynaud's disease at the original visit to the clinic and 58 (32 per cent), a correct diagnosis of Raynaud's disease. This is an unexpectedly large number of men for whose condition the diagnosis of Raynaud's disease made at the time of their original visits could be considered correct by accepted criteria. This observation is especially significant inasmuch as the diagnosis usually had been made by clinicians who were not especially experienced in the field of peripheral vascular disease.

We were able to obtain satisfactory follow-up information either by letter or by re-examination concerning 100 of the 181 men. Our study of the original case records of these 100 men led us to conclude that the diagnosis of Raynaud's disease which was made at the time of the original visit was adequate in 34 cases, questionably adequate in 54 , and almost certainly incorrect in 12. On analysis of the follow-up data, it was considered that the diagnosis of Raynaud's disease could now be made unquestionably in 59 cases, that the diagnosis was still questionably adequate in 9 , and that it was incorrect in 32. Thus in 59 (67 per cent) of the 88 cases in which the original diagnosis should have been Ryanaud's disease or questionable Raynaud's disease, the follow-up study verified a diagnosis of Raynaud's disease, according to the usually accepted criterion for making this diagnosis.

These data indicate that Raynaud's disease occurs more commonly in men than is usually considered and that if the criterion as emphasized by Allen and Brown is followed in making the original diagnosis of Raynaud's disease, the diagnosis, when made in men, will be verified by the passage of time in a high percentage of cases.

The Influence of Humidity on the Survival of Influensa $A$ Virus in Air and Dust.* By Clayton G. Loosu, Elizabeth Appei, Henry M. Lemon (by invitation), and O. H. Roberson, Camp Carson, Colo.

Influenza $A$ infections in mice can be readily produced by allowing them to breathe air contaminated with the virus. The virus-laden atmospheres were produced (1) by spraying suspensions of virus (PR8 strain) prepared from infected mouse lungs, as fine droplets into a room of 800 cubic feet capacity, and (2) by raising dust from the floors of the room into which virus had been sprayed many hours or days previously. With the introduction of approximately the same amount of virus suspension at a given temperature $\left(27^{\circ}\right.$ to $30^{\circ} \mathrm{C}$.) but at varying

* From the Department of Medicine, University of Chicago, Commission on Influenza and Commission on Air-Borne Infections, Board for the Investigation and Control of Influenza and Other Epidemic Diseases in the U. S. Army, Office of the Surgeon General, Preventive Medicine Service. relative humidities, it was found that atmospheres with humidities of from 80 to 90 per cent were infective for mice for only 1 hour, while those at 45 to 55 per cent were infective for 6 hours. Atmospheres of low humidities (17 to 30 per cent), however, were infective for as long as 48 hours and the virus could be isolated from the dust 5 days after its introduction into the room air. Lethal concentrations of virus suspended in atmosphere of low humidity and present in the floor dust were rendered noninfective by raising the humidity 65 per cent or higher for 2 hours. Atmospheres containing insufficient virus to produce influenza in mice as a result of a 20 -minute exposure were found to be highly infective if the mice were allowed to remain in the virus-containing air for 1 hour. These observations support the accumulating evidence that contaminated air may be an important vehicle for the spread of infectious agents and suggest certain possibilities as to their control.

\section{Effects of Dilution and of the Addition of Dextrose on} the Rate of Hemolysis in Stored Blood. By ElMmR L. DeGowin and (by invitation) Irving Frredman, Iowa City, Iowa.

It has been previously reported that the modified RousTurner mixture of 10 volumes of blood, 2 volumes of 3.2 per cent sodium citrate, and 13 volumes of 5.4 per cent dextrose solution permitted storage of blood for transfusion for 30 days at 2 to $5^{\circ} \mathrm{C}$. Many other dextrose-citrate mixtures have been introduced in attempts to secure maximum preservation with reduced bulk. This object is particularly desirable when problems of military transportation are encountered.

In blood-dextrose-citrate mixtures with a blood:diluent ratio of 1:0.3 varying the dextrose concentration from 0.38 to 4.9 per cent resulted in no significant difference in the rate of spontaneous hemolysis during storage at 2 to $5^{\circ} \mathrm{C}$. for 30 days. Mixtures with blood :diluent ratios from $1: 0.3$ to $1: 2.3$ were studied in which the rate of spontaneous hemolysis increased proportionately when the following diluents were employed with blood-citrate: sodium chloride, sodium citrate, human albumin + sodium chloride, human albumin, sucrose, and dextrose. Minimum hemolysis was obtained during $\mathbf{3 0}$ days with dextrose and albumin. The addition of dextrose in the concentration of $200 \mathrm{mgm}$. per cent improved storage in all mixtures. The use of electrolytes increased the rates of hemolysis.

The formation of inorganic phosphorus in the erythrocytes was much greater when dextrose was not added but this fact could not be correlated with the inhibition of hemolysis by sucrose.

It is concluded that the addition of dextrose may serve a dual function in the preservation of blood, by acting as a substrate for glycolysis and by dilution of the plasma with a non-electrolyte. Dilution of the plasma is an important factor in the preservation of blood. The optimum dilution is in excess of a blood :diluent ratio of $1: 1$. 
Simultaneous Arterial and Venous Blood Cultures in Cases of Bacterial Endocarditis. Evidence on the Sites of Removal of Bacteria from the Circulating Blood. By PaUl B. Beeson and (by invitaiton) James V. Warren and Emmett S. Brannon, Atlanta, Ga.

Observations were made on 5 patients with bacterial endocarditis, in an attempt to ascertain the places where bacteria are removed from the circulating blood. Colony counts in cultures of arterial blood were compared with colony counts in venous blood taken at the same time. The venous samples were drawn not only from superficial and deep vessels of the extremities, but also from the superior and inferior vena cava, the right auricle, the hepatic and renal veins. To secure these samples from the venous circulation of the trunk, a flexible ureteraltype catheter with an angled tip was passed, under fluoroscopic guidance, through an arm vein into the superior vena cava and right auricle, whence it could be guided into the other vessels mentioned.

It was found that mixed venous blood in the right auricle usually contained only about half as many bacteria as were present in arterial blood. During periods of 1 or 2 hours, serial specimens of arterial blood showed relatively constant colony counts; thus it appears that in bacterial endocarditis, organisms are being discharged into the circulation more or less steadily. Blood from the hepatic veins always gave strikingly low counts, sometimes only 2 to 5 per cent of the corresponding arterial level. In the superior vena cava, the renal and femoral veins, colony counts were from one-half to three-fourths as high as in the corresponding arterial samples. On the other hand, there was little difference between the colony counts in arterial and antecubital vein blood.

Physiologic Effects of Pufified Gas Gangrene Toxins.* By Austin M. Brues, and (by invitation) Alfred Pope, Paul C. Zamecnik, Abby L. Nutt, Ira T. Nathanson, and Joseph C. Aub, Boston, Mass.

Because of the frequency of clostridia in battle wounds and the readiness with which they multiply and produce toxin in anoxic muscle, we have investigated the possible influence of their toxins in shock. Experiments have been done on dogs, with continuous recording of the blood pressure and oxygen consumption, determinations of hematocrit, plasma protein concentration, cardiac output, peripheral vascular resistance, venous pressure, and plasma volume. Local fluid loss was estimated by measurements of leg volume, and electrocardiograms have been made.

Following intravenous injection of $\mathrm{Cl}$. perfringens toxin (above 200 mouse m.l.d.), blood pressure declines sharply and there is massive intravascular hemolysis followed by escape of hemoglobin from the plasma. Smaller doses result in a transitory drop in blood pressure and partial hemolysis.

* Work done under contract with the Office of Scientific Research and Development.
Intramuscular toxin may also be fatal, but with little or no hemolysis; death can be attributed to shock due to local loss of intravascular fluid. Only 12 mouse m.l.d. injected into one gastrocnemius has caused local loss of approximately 18 per cent of the plasma. This suggests that minimal local gas gangrene infection might produce or aggravate the shock syndrome due to loss of circulating plasma.

Penicillin in the Treatment of Meningitis. By David H. Rosenberg and (by invitation) Phillip A. Arling, Great Lakes, Ill.

The clinical effectiveness and minimum adequate dosage requirements of penicillin were studied in 57 patients with cerebrospinal fever ( 13 with meningococcemia), in 2 patients with hemolytic streptococcal meningitis (1 with bacteremia), and in 1 patient with streptococcus viridans meningitis with bacteremia.

Penicillin, administered both intrathecally $(10,000$ units every 24 hours) and parenterally (10,000 to 15,000 units every 3 hours), produced a rapid clinical response with recovery in 59 out of 60 patients. The one fatality occurred in an individual who was moribund on admission and who presented signs of well advanced meningitis with meningococcemia and secondary hydrocephalus.

In the majority of instances, 10,000 to 20,000 units of penicillin intrathecally resulted in recovery, whereas in the more fulminating types of infection 30,000 to 50,000 units were required. Meningococcemia was controlled with 40,000 to 250,000 units, the maximum dose having been used in the fulminating infections. Sterilization of the blood was found in the patients with streptococcic bacteremia after 110,000 units, but penicillin was continued until 300,000 to 400,000 units were administered. Parenteral penicillin was not effective in the prevention and treatment of acute epididymitis and epididymoorchitis complicating cerebrospinal fever, nor in the treatment of acute meningococcic fibrinous pericarditis or arthritis.

Factors Influencing Acclimatization and Performance in Humid (Tropical) Heat. By William BenNetT BeAN, Ludwig W. EIchNA, and (by invitation) William F. Ashe, and Norton A. Nelson, Fort Knox, Ky.

A study of heart rate, blood pressure, rectal and skin temperatures, changes in blood and urine, subjective sensations, and related phenomena, has been made in 64 men during acclimatization to work (marching at 2.5 miles per hour with a 20 pound pack) in humid heat $\left(90^{\circ}\right.$ to $91^{\circ} \mathrm{F}$; ; relative humidity 95 per cent $)$. The acclimatized man works with a lower heart rate, lower skin and rectal temperature, more stable blood pressure, and less discomfort than when unacclimatized. Strenuous or protracted work is not well tolerated initially. Acclimatization begins with first exposure, is facilitated by a gradual increase in work, and is nearly complete in 3 to 10 days. Early intolerance to heat does not retard 
or prevent acclimatization if rest, water, and salt are supplied. Resting in humid heat induces but little acclimatization. It develops most rapidly in subjects entering the hot room in summer and is retained longest in summer. Cross acclimatization between desert and tropical heat exists. Performance in humid heat is impaired by (1) lack of acclimatization, (2) added clothing, (3) lack of rest and sleep, (4) water deprivation (thirst is an inadequate guide to requirement), (5) lack of physical fitness, (6) alcohol, (7) long periods of work, and (8) slight increases in humidity and temperature.

Compensatory Peripheral Vascular Adjustments During Spinal Anesthesia.* By Charles NeumanN (by invitation), AlberT D. Foster, JR. (by invitation), Emery A. Rovenstine (by invitation), and Alfred E. Corn, New York, N. Y.

The plethysmogram of fingers and toes has two principal waves: (1) Pulse waves, and (2) alpha waves (rhythmic variations in volume occurring 4 to 8 times per minute). Normally the pulse wave-alpha wave patterns of fingers and toes correspond and change similarly in response to physiologic stresses associated with alterations of sympathetic activity.

To demonstrate the influence of the sympathetic nerves, regional anesthesia was induced by the spinal route in 15 normal individuals. The areas (toes) deprived of sympathetic stimuli increased in volume, pulse waves increased 2 to 3 times and alpha waves disappeared (vasodilatation). Concurrently, areas (fingers) still under the influence of active sympathetic innervation showed decrease in volume, decrease in pulse waves to one-third their former size, and decrease in alpha waves (vasoconstriction). Blood pressure and pulse rate remained constant. These observations suggest that vasodilatation in any considerable peripheral vascular bed is accompanied by compensatory vasoconstriction elsewhere.

In 4 subjects under spinal anesthesia, a fall in blood pressure occurred. It was preceded by relaxation of the usual vasoconstriction in the unanesthetized fingers. Administration of ephedrine to these subjects was followed by return of vasoconstriction in the fingers, and then by elevation of blood pressure. Vasodilatation in the toes was unaltered during the depression of blood pressure or its subsequent rise.

The Relative Constancy of Inulin and Diodrast Clearances. By George F. Koepf, Roger S. Hubbard, and Ted Looms (introduced by David K. Miller), Buffalo, N. Y.

A statistical analysis was made of the results of simultaneous inulin and diodrast plasma clearances obtained in 79 separate 15 minute test periods upon 19 subjects. The experiments were carefully carried out to insure satisfactory collection of blood and urine

* The Bureau of Medicine and Surgery does not necessarily undertake to endorse views or opinions which are expressed in this paper. samples. It was found, when the individual clearance periods were studied, that the inulin clearance, taken to be a measure of glomerular filtration, showed greater constancy than did the diodrast clearance, which is regarded as a measure of the plasma flow to active kidney tissues. The coefficients of variation were; for the inulin clearances: $39 \pm 2.4$, and for the diodrast clearance: $55.2 \pm 3.8$. The difference between these values has a 98 per cent probability of being statistically significant. The authors believe that the greater constancy of the inulin clearance arose largely from regulation of the glomerular filtration of the individual subjects, for when the results upon each subject were averaged, and these averages analyzed statistically, the coefficients of variation of inulin and diadrast clearances were $31.9 \pm 3.8$ and $39.9 \pm 5.0$, respectively.

Hypersplenism. By William Dameshex, Boston, Mass.

Following splenectomy, various changes develop in the morphologic elements of the blood. The red cells become thinner and show Howell-Jolly bodies; the white cells and platelets become increased. Splenomegaly is often accompanied by anemia, leukopenia, and thrombocytopenia in the presence of a hyperplastic bone-marrow; following splenectomy, sharp increases in the red cells, white cells, and platelets usually take place. These observations suggest $(a)$ a relationship between the bone-marrow and the spleen and $(b)$ a possibly enhanced relationship ("hypersplenism") in cases of splenomegaly. In cases of idiopathic thrombopenic purpura without splenomegaly, the marrow is crowded with unproductive megakaryocytes which, following splenectomy, show extreme platelet production. In certain cases of granulocytopenia, with or without splenomegaly, the marrow is crowded with leukocytes; following splenectomy, both the marrow and the blood become normal. These cases, and certain types of hemolytic anemia reacting quickly to splenectomy, suggest the possibility of abnormal types of hypersplenism. Although there is much indirect evidence indicating the presence of splenic hormones, direct evidence is scant. Studies of parabiotic material, the further preparation of splenic extracts from normal and abnormal cases, and the development of anti-splenic serum show promising results in this direction.

Gastric Excretion of Sulfadiazine In Man. Observations on Normals, Patients with Peptic Ulcers, Atrophic Gastritis, and Gastric Cancer. By LeoN SchIrF, Nathan Shapiro (by invitation), and Henry S. Block (by invitation), Cincinnati, Ohio.

The concentration of sulfadiazine in the blood and gastric juice was determined in 43 subjects following intravenous injection of $\mathbf{5}$ grams of sodium sulfadiazine in $300 \mathrm{ml}$. of physiological saline. The gastric juice was obtained by continuous aspiration for a period of an hour and a half or more. The subjects included 7 normals, 15 with peptic ulcer, 8 with atrophic gastritis, and 13 with gastric cancer. 
The concentration of sulfadiazine in the gastric juice of patients with gastric cancer and achlorhydria tends to be higher than in normal individuals, patients with gastric or duodenal ulcer, or patients with atrophic gastritis, with or without achlorhydria. The concentration of sulfadiazine in the gastric juice of patients with gastric cancer is roughly proportional to the extent of the tumor.

The Mechanism of Shock Produced by the Injection of Trypsin, Thrombin, and a Proteolytic Plasma Preparation. By Henry J. TAGnon (introduced by - George R. Minot), Boston, Mass.

Crystalline trypsin, in vitro, accelerates the coagulation of normal and hemophilic blood. In vivo, however, as shown by Dragstedt and Rocha E. Silva, in dogs and rabbits, it prolongs the clotting time and produces shock. The prolongation of the clotting time has been ascribed by these authors to the presence of heparin. The work here presented is an attempt to elucidate by what mechanism the clotting action of trypsin observed in vitro can prolong the clotting time in vivo, and what part it has in the production of shock.

The data show that the prolongation of the clotting time following intravenous injection of trypsin into dogs and rabbits is accompanied by a marked hypothrombinemia and fibrinogenopenia and is not due to the production of some anticlotting agent.

Thrombin and a homologous plasma preparation having properties, similar to trypsin, which accelerate the clotting time in vitro, likewise produce hypothrombinemia and fibrinogenopenia with prolongation of the clotting time when injected intravenously. The mechanism seems to be the promotion of a progressive intravascular coagulation resulting in the consumption of fibrinogen and prothrombin, although no clot may be seen at autopsy. The absence of clot is understandable if the fibrin formed is uniformly deposited on the enormous surface of the endothelial wall. This is further indicated by the preventive action of heparin on the prothrombin and fibrinogen changes following intravenous injection of any of the three clotting agents.

Thrombin differs, however, from the two other agents in that its vaso-depressive (shocking) action is entirely abolished by the preliminary administration of heparin, which renders milder but does not abolish the vasodepressive action of trypsin and the plasma enzyme preparation. This indicates that the vaso-depressive action of thrombin is abolished when clotting is prevented and is presumably entirely due to its clotting action, which accounts for only part of the vaso-depressive action of trypsin and the plasma enzyme.

Human Requirements for Thiamin and Riboflavin. By Victor A. NAJJAR (by invitation) and L. EMMETT Holt JR., Baltimore, Md.

Experiments have been undertaken on human subjects on synthetic diets in which all $B$ vitamins have been supplied as pure compounds, thus eliminating the error caused by the highly variable quantities of these vitamins in natural foods.

Data have been obtained showing : (1) the daily quantities of thiamin and riboflavin required to protect sedentary adults from deficiency, (2) the effect of biosynthesis of vitamins by intestinal bacteria on the daily requirement, and (3) the effect of varying the composition of the diet on biosynthesis of these vitamins.

\section{Changes Produced by Gonadotropins in Long-Standing Cases of Hypopituitarism. By JACOB LERMAN and (by invitation) Ira T. Nathanson, Boston, Mass.}

The effect of gonadotropins was evaluated in a study of the therapy suitable for patients with hypopituitarism. Two males, ages 46 and 48 , showed definite clinical and laboratory response after the administration of chorionic gonadotropin. The clinical change consisted of increased physical energy, change in the psyche, development of libido, erections, and sexual potency for the first time in many years, and enlargement of the genitals and gonads. In one of these patients, administration of thyroid hormone may have enhanced the gonadotropic effect. The laboratory evidence consisted of a definite rise in the excretion in the urine of the 17-ketosteroids during the period of treatment. Testicular biopsies demonstrated slight but definite increase in activity in the tubules.

On omission of therapy, there was a fall in the excretion of the 17-ketosteroids and a regression of the clinical improvement.

One woman, age 47, with profound hypopituitarism (Sheehan's Disease) of 17 years' duration, failed to respond to gonadotropic therapy. This is in contrast to the excellent response from gonadotropic hormone in another patient, previously reported, who was 29 years of age, with the disease of 7 years' duration.

It is concluded that the gonads of adult patients with hypopituitarism respond in some instances to gonadotropic therapy.

\section{Leg Venograms in the Course of Operation for} Hysterectomy. By David Davis and (by invitation)

A. Stone Freedberg, Boston, Mass.

In a previous study lower leg venous pressure increases were demonstrated during operations for hysterectomy. To examine the possibility that these increases were due to local spasm of the veins of the legs, 13 venograms were made during 4 operations for hysterectomy using the technic of Bauer.

In one, the venograms showed normal filling of the deep veins. In another, filling was normal except for one small segment. A second venogram taken later showed excellent filling.

In 2 other operations, there were marked filling defects of the deep veins. In one, 5 venograms during and shortly after operation for the removal of a large fibroid showed a changing picture, varying from absent to partial filling with narrowing and breaks in continuity. In the 
remaining case, 3 venograms during the operation likewise showed little or no filling of the deep veins, although the saphenous and communicating branches were visualized. Several hours later, a venogram showed good filling of the upper half of the deep veins.

The filling defects noted differed in no way from those obtained in the presence of deep vein thrombophlebitis. They were not considered artefacts, for experience with the Bauer technique has shown that the deep veins fill regularly when the small saphenous vein is properly injected and visualized.

The Effect of Desoxycorticosterone Acetate On the Blood Pressure of Man. By George A. Perera, Abbie I. Knowlton, Alice Lowell (by invitation), and RoBert F. LoEB, New York, N. Y.

Attention has been called by many authors to the production of hypertension in animals and in patients with Addison's disease following the administration of desoxycorticosterone esters. It has not become apparent whether the increase in blood pressure is due to salt and water retention or to some other unexplained activity of the hormone.

The effects of desoxycorticosterone acetate (DCA) and of sodium chloride, upon the blood pressure, blood volume, and sodium concentration of the blood, were therefore.studied in comparable groups of patients with Addison's disease and in 3 patients without demonstrable adrenal or cardiovascular disease.

No hypertension appeared in 15 patients with hypoadrenalism maintained in electrolyte balance with sodium chloride alone for an average of more than 3 years. Eleven of 23 patients with Addison's disease, maintained in electrolyte balance with DCA, developed blood pressure levels repeatedly in excess of 140/90, 4 of these being excluded from consideration because of the possibility of antecedent cardiovascular disease. The 3 patients with no adrenal disease showed a significant rise in blood pressure following DCA after preliminary control observations.

The elevation of blood pressure could not be correlated with excessive retention of salt water in the circulating blood or to a labile vascular system as manifested by a positive cold pressor test. It therefore seems probable that DCA acts directly or indirectly upon the peripheral vascular system.

\section{A Simple, Rapid, Quantitative Method for Determination} of Penicillin. By Edwin E. Osgood and (by invitation) Barbara Gamble, Portland. Oregon.

The method to be described is satisfactory for determination of penicillin in pure solution, penicillin cultures, cerebrospinal fluid, blood serum, urine, or tissue fluids. Results are obtainable within 2 to 3 hours, and it is possible to measure as little as 0.001 unit per $\mathrm{ml}$. The optimal sensitivity is in the region of 0.04 unit per $\mathrm{ml}$. to which all higher concentrations may be diluted. In concentrations between 0.02 and 0.08 units per ml., the accuracy with research care is about plus or minus 5 per cent, and with ordinary clinical technic it is about plus or minus 10 per cent. The method is also suitable for the quantitative comparison of chemotherapeutic agents. The mathematical formulae on which the determination is based give quantitative data on the interrelationship between bacterial numbers and penicillin activity.

Changes in the Electroencephalogram Produced by Sodium Amytal and Sodium Pentothal. By MARY A. B. Brazier (by invitation) and JACOB E. Finesinger, Boston, Mass.

The use of sodium amytal and pentothal in the treatment of war neuroses has stimulated further interest in the mechanism of their action.

Sodium amytal and pentothal when administered intravenously in a series of 20 psychoneurotic patients produced an almost immediate and very marked change in the electroencephalogram which is obvious on gross inspection. It consisted most markedly of the development of high-voltage fast activity (i.e., potentials of 24 to 28 cycles per second and of 150 to 200 microvolts). There was a specificity for waves of this frequency. At higher concentrations of the drug, slow waves of delta frequencies appeared.

The use of a method entailing an accurate measurement of electroencephalograms has been applied to establish the distribution of individual frequencies in these drug records. This method has revealed that the characteristic high-voltage activity appears first and most prominently in the frontal leads, and proceeds gradually to the parietal and occipital leads. On recovery from the drug, the progression is in the reverse direction, and the effect lingers most persistently in the frontals. These waves disappear with the onset of sleep and reappear if the patient is roused. The progression in the cortex is too slow to be explained by differences in cerebral circulation. These waves occur first and are most prominent and persistent in those parts of the cortex which are of the most recent phylogenetic development.

The Leukocyte Count in Primary Atypical (Virus) Pneumonia. By Ovid O. MeYer and (by invitation) Ethel W. Thewlis, Madison, Wis.

Since the diagnosis of primary atypical pneumonia (virus pneumonia) is necessarily dependent on the clinical and roentgenological findings and the exclusion of other types of pneumonia, rather than by conclusive bacteriological methods, any additional diagnostic aid might be welcome. With the hope of discovering further help in the laboratory, careful detailed studies of the blood counts were made. The usual methods were employed. Initial complete blood counts and hematocrit determinations were made, and thereafter leukocyte counts with differential counts of 500 cells on Kingsley stained smears were done thrice weekly, or oftener, in 50 patients.

The characteristic but not invariable findings in the 
initial leukocyte counts were as follows: normal total leukocyte count with an increase in neutrophiles and monocytes (large mononuclears) and a lymphopenia; eosinophilia in 26 per cent of the cases that had initial counts made relatively late in the course of the disease.

As the patients improved, the total leukocyte count usually increased, often to above normal level, and the neutrophiles, lymphocytes, and monocytes tended to resume normal relationships.

It appeared that the monocytosis in primary atypical pneumonia was perhaps the most significant of the findings and in association with the other blood findings, might have some diagnostic significance.

Evidence Bearing on the Mechanism of Certain Atrial Arrhythmias. By GeORGe Decherd and (by invitation) Arthur Ruskin, Galveston, Tex.

Barker et al. have recently summarized the evidence which supports the view that paroxysmal atrial tachycardia is the result of a circus movement. The rather frequent close association of tachycardia with flutter or fibrillation inclined us to the idea that all three arrhythmias might have a similar physiologic basis. This possibility has been put to one test by using a slight modification of the method by which Lewis, Drury, and Iliescu in 1921 demonstrated a circus movement in clinical flutter and fibrillation.

Simultaneous electrocardiographic tracings have been made of two leads in each of three planes in the chest, i.e., frontal, horizontal, and sagittal. These tracings have been enlarged by projection, and from them we have calculated the electrical axes of the atrium for each $1 / 100$-second. These axes have been diagrammatically arranged to show the serial change in the directions of consecutive axes in each plane, and from them threedimension models have been constructed.

With this procedure, we have studied the curves of the momentary atrial axes in patients with sinus rhythm, with and without various types of heart disease; and in patients with atrial flutter, fibrillation, and paroxysmal tachycardia. The curves derived from flutter show characteristically a return to their initial direction, and form a roughly circular diagram; those from fibrillation show this same essential feature, though they are much more irregular. The curves from paroxysmal tachycardia resemble those from sinus rhythm, differing only in their direction; neither show any tendency to return to their initial direction, or to inscribe a circus. We have interpreted these findings as favoring the view that paroxysmal tachycardia is the result of an ectopic pacemaker, rather than of a circus movement.

The Increase of Cytochrome $C$ Content of Organs Following its Parenteral Injection. By S. Proger and (by invitation) D. Decaneas and G. Schmidt, Boston, Mass.

The influence of the concentration of cytochrome C on the activity of cytochrome oxidase has recently been studied by Stotz, Altschul, and Hogness (1938) and by Schneider and Potter and others (1943). When the results of these investigations are compared with the amounts of cytochrome $\mathrm{C}$ and cytochrome oxidase in the tissues, especially in heart, brain, liver, and kidney, it appears that the cytochrome contents in these organs range far below the concentrations . required for the maximal activity of the cytochrome oxidase present. It is, of course, possible that the effectiveness of the total cell respiration is determined by limiting factors other than the activity of the cytochrome-cytochromoxidase system. Nevertheless, the apparent existence of suboptimal conditions for the action of this system in normal tissues seems to justify the attempt to investigate the physiological effects of experimental conditions designed to increase the rate of action of cytochrome oxidase as by supplying additional cytochrome.

Cytochrome $\mathrm{C}$, extracted from beef hearts, was injected into rats intravenously, intraperitoneally, and intramuscularly. This results in a definite increase in the content of cytochrome $C$ in the brains, kidneys, livers, and hearts, the pattern of increase and subsequent decrease in the various organs varying, depending upon the mode of administration and experimental conditions such as anesthesia and anoxia.

Cytochrome $\mathrm{C}$, given intravenously to dogs, appears to increase the arterio-venous oxygen difference under conditions of anoxia presumably because it stimulates increased tissue respiration and hence removal of oxygen from the blood stream.

It is suggested that respiratory enzymes such as cytochrome $\mathrm{C}$ might be studied further with the hope of employing them in the attack on the problems of tissue anoxia, both acute and chronic.

Acute Respiratory Disease in the Canadian Army. By W. R. FEAsBY (introduced by W. Hurst Brown), Ottawa, Ontario, Canada.

These studies were conducted, during 1943, at Camp Borden, Ontario, an area where good sampling was possible.

(1) Losses for acute respiratory disease in the Canadian Army are calculated for 200,000 men serving in Canada as follows:

(a) Half a million hospital days

(b) One million duty days

(c) $\$ 5,800,000$ hospitalization costs

(d) Three per cent (of all who fell ill) discharged, and 0.1 per cent dead in 6 months.

(2) Causes

A. Environmental-High respiratory sick rates coincided with:-

(a) Bad weather

(b) Bad quartering and poor dust control

B. Etiological agents

(a) Virus-In February non-influenzal infections occurred. Twelve per cent of patients had pneumonia. Mice and ferrets had minimal lung lesions. In April, a 
small influenza A epidemic occurred. A widespread A epidemic occurred in November.

(b) Streptococcal-From cases of scarlet fever, tonsillitis, pharyngitis, etc., 1200 streptococcal groupings and typings were done. Up to 85 per cent of acute respiratory infections were associated with group $A$ haemolytic streptococcal infections. Type 19 (17) predominated. Scarlet fever had less type scattering than other streptococcal illnesses. Specific types were not incriminated in the complications, but five out of seven patients with nephritis had type 14 associated. Hospital cross-infections were frequent. Scarlet fever did not produce complications more often than other streptococcal infections. Half of the 100 cases of polyarthritis are now discharged. Two are dead.

\section{(3) Control Measures}

These include dustless sweeping and cleaning of barracks, and proper blanket care, which have been enforced by an educational campaign since June, 1943.

Influence of Aspirin on Urate Excretion. By FRIEDRICH KLemperer (by invitation) and Walter Bauer, Boston, Mass.

Acetyl-salicylic acid (aspirin) has been used widely to lower the serum uric acid concentration in patients with gout. Therefore, the effect of aspirin on serum urate level and urate excretion was studied. On 7 occasions, daily doses of aspirin of 5 grams or more were administered to 3 patients with hyperuricemia due to gout and to 2 normal subjects. This resulted in a decrease of serum urate concentration of 42 to 75 per cent. This could be accounted for by increased renal excretion. Small doses of aspirin of 2 grams per day were given to the 3 patients with gout on 6 occasions. In all these instances, the serum urate level increased by 37 to 69 per cent. This rise in serum urate level was due to a temporary decrease in excretion. Small amounts of aspirin had only a slight and possibly insignificant effect in raising serum uric acid in normal individuals. One gouty subject was encountered whose serum urate concentration was entirely uninfluenced by the administration of aspirin.

The mechanism of the action of aspirin on renal excretion of urates was studied. It was found not to be a change in the ability of the kidneys to concentrate urates, since the maximum urinary urate concentration, obtained during urine concentration tests, remained unaltered when aspirin was given. Although renal urate clearance is highly variable, the maximum value during a 24-hour period remained inversely proportional to the serum concentration. The administration of alkali along with the aspirin in no way altered the effects described.
Meningococcal Arthritis: A Clinical Study. By WIILIAM W. Beckman (by invitation) and Marian W. Ropes, Boston, Mass.

Certain features of meningococcal arthritis which set it apart from other types of infectious arthritis were observed. Ten of 34 cases of proved meningococcal infection had articular involvement. This incidence of 29 per cent is considerably higher than has been reported. In every case in which joint involvement occurred, meningococci were grown from the blood stream and in all but one a typical purpuric skin rash was present.

The arthritis was usually asymmetrical and, in general, involved only 1 or 2 of the larger joints. The affected joints were swollen and sometimes limited in motion, but in no case were they red or hot. Pain was slight and at times the patient was not aware of joint disease until it was pointed out on physical examination. This was in distinct contrast to the evidence of inflammation in the synovial fluid where leukocyte counts ranging between 760,000 and 42,000 were found at the time of the first observation. In spite of the purulent effusions, it was exceedingly difficult to cultivate the organism, which was obtained from only 1 aspiration in 1 patient. Fourteen subsequent aspirations during 6 weeks in the same patient yielded purulent fluid from which no organism could be grown by any technic.

Another striking characteristic of this arthritis is its failure to respond to sulfonamide therapy. In every case, the meningitis and septicemia responded rapidly to the drug, but the arthritis persisted, and, indeed, on two occasions developed, after the other signs of meningococcus infection had subsided. Seven cases were treated with sulfonamides alone. The drug was continued until the arthritis, whose average duration was 6 weeks, had subsided. Two cases were treated with both sulfonamides and antimeningococcus serum and the arthritis lasted less than one week in both cases. It is possible that serum may be the method of choice for combatting meningococcal arthritis. It is of interest that none of our patients suffered permanent joint damage.

\section{Plasma Antithromboplastic Activity after Severe Hemorrhage. By L. M. Tocantins, Philadelphia, $\mathrm{Pa}$.}

In patients who have had severe blood loss for some time, the antithromboplastic activity of the plasma is markedly reduced. This and the frequently coincident thrombocytosis may account for the hypercoagulability of the blood which often follows hemorrhage. Diminution in plasma antithromboplastic activity and thrombocytosis may be important contributory factors in the production of vascular thrombosis. Blood or plasma of low antithromboplastic activity usually clots at the same rate whether placed in plain glass or paraffin coated tubes. The blood of individuals who have had severe hemorrhages, and plasma from which antithromboplastin has been removed by contact with adsorbents, often display the same characteristics. The clot accelerating action of a water wettable surface (e.g., glass) seems 
to result, at least partly, from an inactivating effect of the surface contact on the plasma antithromboplastin.

The excess of antithromboplastin responsible for the reduced coagulability of hemophilic blood may also contribute to the exaggeration of the difference between the rate of coagulation of this blood in plain glass tubes as contrasted to paraffin coated tubes.

The Use of Deracil (2-Thio-6-Oxypyrimidine) in the Treatment of Toxic Goiter. By S. L. GARGILL and (by invitation) M. F. Lesses, Boston, Mass.

The anti-thyroid effects of Deracil (2-thio-6 oxypyrimidine) have been investigated clinically in 29 patients with toxic diffuse goiter, and 5 patients with toxic nodular goiter. As complicating factors, 1 patient had pernicious anemia in remission; 1 had mitral stenosis with auricular fibrillation; 2 had hypertensive heart disease; and three had paroxysmal auricular fibrillation.

The majority of the patients were initially hospitalized for 2 weeks. During this period, the B.M.R. level before treatment was established, following which Deracil was administered. The B.M.R. was measured at weekly intervals and leukocyte counts were done on alternate days with differential counts if the total leukocyte count fell below 4000 per c. $\mathrm{mm}$.

Deracil was administered in doses of 0.6 to $0.8 \mathrm{gram}$ daily. The dosage was reduced to 0.1 or $0.2 \mathrm{gram}$ daily as normal or subnormal levels of metabolism were attained. All patients received high calorie diets and occasional small doses of sedatives. Digitalis or quinidine sulphate were given when indicated.

Clinical improvement, as measured by the fall in metabolic rate, weight gain, and decreased pulse rate, usually occurred 2 weeks after Deracil was started, and was fairly complete at the end of 1 month. The goiters decreased in size and became softer and eye signs improved.

In 4 patients, there was initial aggravation of symptoms and signs for several days. Four patients developed myxedema which disappeared upon omission of Deracil. Two patients developed bilateral enlargement of the submaxillary glands, accompanied by slight fever. This complication improved within 1 week despite continuation of therapy. Two patients developed drug fever, which disappeared upon omission of Deracil. One patient, a woman aged 57, developed agranulocytosis after taking Deracil, $0.2 \mathrm{gram}$ daily, for 6 weeks. While definitely recovering from the agranulocytosis, she suddenly died from tracheal mucus plug and pulmonary atelectasis.

Deracil is an effective but treacherous antithyroid drug.

Treatment of Toxic Goiter by Irradiation of the Pituitary. By WILLARD $O$. THOMPSON and (by invitation) Phebe K. Thompson, Chicago, Ill.

Ever since the demonstration of the thyrotropic activity of the pituitary there has been great interest in its rôle in toxic goiter. During the past several years, we have observed the effect of irradiation of the pituitary in 38 patients with toxic goiter. In 7 of them, the metabolism dropped permanently to within normal limits. In 16, a temporary reduction in metabolism of from 15 to 52 points was observed. In 15 patients, there was no change. These observations appear to support the hypothesis that in some patients with toxic goiter, the anterior lobe of the pituitary stimulates the thyroid to overactivity. While the results of treatment with thiourea, thiouracil, and radioactive iodine are very important, these materials do not appear to attack the underlying cause of the disease.

An Experimental Attempt to Transmit Primary Atypical Pneumonia in Human Volunteers. By Commission on Acute Respiratory Diseases. (Board for the Investigation and Control of Influenza and Other Epidemic Diseases in the Army, Preventive Medicine Service, Office of the Surgeon General, U. S. Army). Presented by Theodore J. Abernethy (introduced by John H. Dingle), Fort Bragg, N. C.

A preliminary experiment has been conducted in human volunteers in an attempt to transmit primary atypical pneumonia. Throat washings and sputa were obtained from 7 hospitalized soldiers manifesting characteristic symptoms, physical signs, and roentgenographic evidence of primary atypical pneumonia. The unfiltered specimens were sprayed into the respiratory tracts of 12 individuals. The volunteers were kept in group isolation for a period of 6 weeks and observed daily for the development of any symptoms and signs of illness.

Respiratory illnesses, varying in clinical manifestations and severity, developed in 10 of the 12 volunteers. In 6 men, symptoms appeared between 5 and 12 days after the first inoculation. Constitutional symptoms of moderate severity were noted by 7 patients. Subcrepitant "sticky" râles were detected in the lungs of 5 patients. Eight volunteers developed fever $\left(99^{\circ} \mathrm{F}\right.$. or above) following the inoculations; in 5 , the maximum temperature was over $100^{\circ} \mathrm{F}$. The roentgenograms of 3 patients revealed definite but minimal pulmonary infiltration. Cold hemagglutinins appeared in the convalescent sera of 3 patients; agglutinins for an indifferent streptococcus (Rockefeller No. 344) did not develop during illness.

Evidence is presented that illnesses closely resembling primary atypical pneumonia developed in certain of those who received the inoculations.

Changes in Vascular Permeability Correlated with the Incidence of Encephalopathy Encountered during the 5-Day Treatment of Syphilis with Mapharsen. By O. Tod Mallery, Jr. (by invitation) and Arthur C. CurTis, Ann Arbor, Mich.

A study of 84 consecutive patients receiving intensive mapharsen therapy for syphilis is reported wherein capillary studies, using both positive and negative pressure tests, were done before and after therapy. The treatment consisted of a total of $1200 \mathrm{mgm}$. of mapharsen given as a slow intravenous drip over a 5-day period. 
A clinical diagnosis of hemorrhagic encephalopathy was encountered in 7 cases and post mortem examination confirmed the diagnosis in 2 fatal instances. This complication occurred in 6 females and 1 male. A positive tourniquet test and a lowered negative pressure reading were found in a majority of the patients at the onset of clinical symptoms. A return to pre-treatment values was observed with recovery.

No significant difference was observed between the pre- and post-therapy whole blood vitamin C levels, plasma prothrombin, bleeding, and clotting times. Platelet counts were likewise unaltered.

The finding of a positive tourniquet test in the pretreatment group proved to be a warning of an impending reaction in 3 of 6 patients. The use of the positive pressure test is suggested as an aid in selecting and following patients receiving intensive arsenical therapy.

Hypogonadotrophic Eunuchoidism: Its Physiology, Diagnosis, Prognosis, and Treatment. By CARL G. Heller and Warren O. Nelson (introduced by Elmer L. Sevringhaus), Detroit, Mich.

Hypogonadism in males may be due to a primary defect of the testis or secondary to failure of the gonadotrophic portion of the anterior pituitary. Distinguishing the latter group from the former is of importance in determining prognosis and therapy. Life-long substitutional therapy is needed by individuals with primary leydig-cell failure whereas stimulatory therapy in these cases of hypogonadotrophic eunuchoids may precipitate spontaneous puberty, in which case no further therapy is necessary.

Thirteen cases of hypogonadotrophic eunuchoidism have been studied clinically and routine laboratory studies have been performed. In addition, biopsies of the testes and mammary glands have been studied histologically. Urinary gonadotrophic excretion, 17-ketosteroid excretion, and estrogen excretion have been determined. Review of the results indicated that administration of chorionic gonadotrophins should stimulate leydig-cell function.

Administration of 1500 I. U. daily caused clinical improvement and biopsies performed during therapy indicated marked leydig-cell stimulation and incomplete stimulation of spermatogenesis. Therefore the administration of a purified preparation of follicle-stimulating hormone was added to the therapeutic regime in some cases while injections of chorionic gonadotrophins were continued. This resulted in additional stimulation of the seminiferous tubules and the production of spermato- genesis, which was proved by study of seminal fluid specimens and of testicular biopsies.

The clinical and laboratory features will be described along with suggestions for a therapeutic test to distinguish this syndrome from other types of eunuchoidism.

Effect of Methyl Testosterone on Adrenal Cortical and Testicular Precursors of Urinary 17-ketosteroids.* By E. C. Reifenstein, JR. (by invitation), A. P. Forbes (by invitation), F. Albright, and E. Donaldson (by invitation), Boston, Mass.

Since 17-methyl testosterone is not excreted as a 17-ketosteroid, it was employed to study the effect of a testosterone compound on the endogenous production of urinary 17 -ketosteroids.

The administration of methyl testosterone decreased the urinary 17-ketosteroids of 5 patients in whom the only source of these substances was the adrenal cortices (2 women with adrenal hyperplasia and Cushing's syndrome, 2 women with adrenal hyperplasia and adrenogenital syndrome, and 1 woman with normal adrenal cortical function) and of 1 patient where the only source was the testes (a male patient with Addison's disease).

Since the production of 17 -ketosteroid precursors from both the adrenal cortex and the male gonad is inhibited by the same substance, and if one attributes this inhibition to a decreased production of some pituitary tropic hormone, these findings support the thesis that the same tropic hormone, presumably the lutinizing hormone, stimulates both glands. The $17-$ ketosteroid excretion by patients with the adreno-genital syndrome was less easily influenced by methyl testosterone than was that of patients with Cushing's syndrome. This is further evidence that the elevated 17 -ketosteroid excretion in the former condition is a manifestation of the primary pathology, whereas the increased excretion in the latter condition is an indication of a compensatory process.

The fact that the 17-ketosteroid excretion in the adrehogenital syndrome can be reduced with methyl testosterone gives hope that a non-androgenic steroid may be found which will likewise reduce the 17 -ketosteroid excretion in this condition.

* These studies were supported by grants from the Josiah Macy, Jr. Foundation and from the Committee on Endocrinology of the National Research Council. The work described in this paper was done under a contract, recommended by the Committee on Medical Research, between the Office of Scientific Research and Development and the Massachusetts General Hospital. 